\title{
The Composition of the Poetic Verse in The Poetry of Al Wahb Family
}

\author{
Saad Ali Saleh Al-Shabani*, Muhammad Nuri Abbas \\ Department of Arabic Language, College of Education for Human Sciences, Anbar University, Iraq \\ *saad19h2029@uoanbar.edu.iq
}

\begin{abstract}
KEYWORDS: $\quad$ Verse, Writers, Syntax, Al Wahb, Analysis.
\end{abstract}
Crossref doi https://doi.org/10.51345/.v32i2.394.g220

\begin{abstract}
:
The purpose of this research is to find out the compositional aspects of the poetic verse in the poetry of the family of the Wahb family, who are the class of writers in the Abbasid era. Their literature had a great position, and They performed a prominent role in the fields of literary life. A combination such as the composition of the poetic verse and the composition of the literary text as well as the technical image in simile, metaphor, and metonymy, and their literature also included the phonological level such as rhythm in poetry, poetic weight, rhyme, and internal music, and we preferred to devise and study the compositional aspects of the verses of the poetry of the Al-Wahb family, and composed the research from an introduction and five demands which are: (news, presentation and delay, deletion, interrogation, call) in which I studied the structural level.
\end{abstract}




\title{
تركيب البيت الشعري في شعر أسرة آل وهب
}

\author{
سعد علي صالح الشعبالي*، أ.م.د. محمد نوري عباس

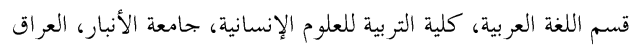 \\ * saad19h2029@uoanbar.edu.iq
}

الكلمات المفتاحية البيت الشعري، الكتّاب، تركيب، آل وهب، التحليل.

Crossref doi) https://doi.org/10.51345/.v32i2.394.g220

\section{ملخص البحث:}

غاية هذا البحث هي الوقوف على الجوانب التركيبية للبيت الشعري في شعر أسرة آل وهب، وهم طبقة الأدباء الكتّاب في

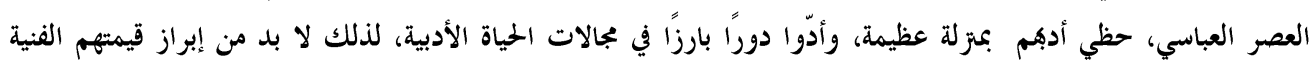

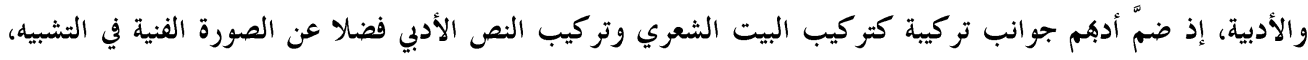

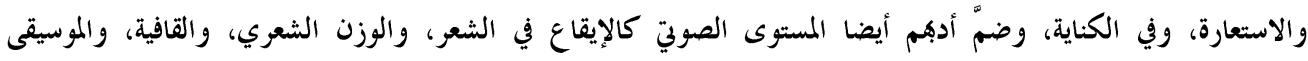

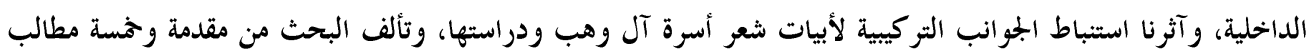

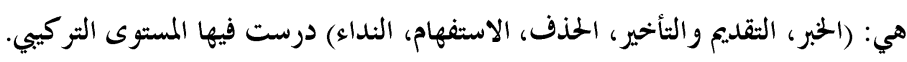

المقدمة:

إنَّ ظهور طبقة الأدباء الكتّاب في العصر العباسي غدا أمراً ملحًا فرضه ذلك التطور الواسع الذي شهدته فئه

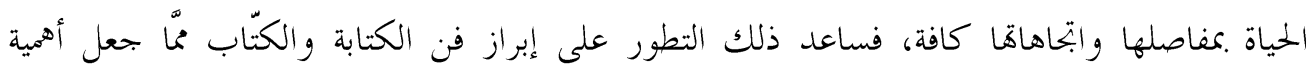

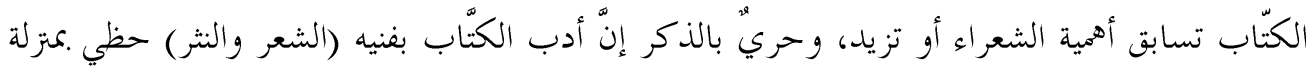

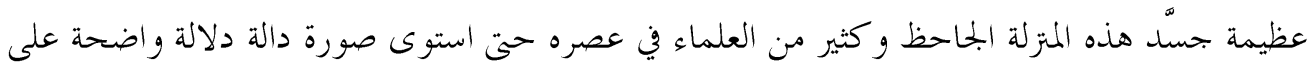
مظاهر الحياة الأدبية والسياسية والاجتماعية.

فمن الأسر الأدبية التي مثلت هذا الأدب (أسرة آل وهب)، وهي وهي من الأسر القليلة التي اعرقت في الكتابة

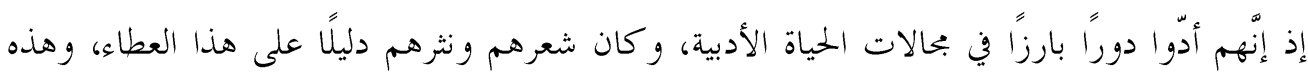
المكانة التي سمحت لفم سياسة العصر التوجه صوب الوزارة، فاستطاعو ا بجنكتهم السياسية وأسلوبمم في

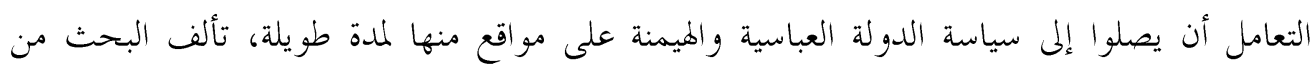
مقدمة وخمسة مطالب هي: (الخبر، التقديم والتأخير، الحذف، الاستفهام، النداء)، وخاتمة. 


\section{تركيب البيت الشعري في شعر أسرة آل وهب}

كانت القصيدة العربية منذ نشأتها الأولى تسير وفق نظام معين إذ اهتم الشاعر العربيت العربي اهتمامًا بالغًا ببناء قصيدته، وأولاها أهمية وعناية؛ لأن القصيدة تتكون من أسلوب يقدم التجربة الشعرية للشاعر سواء

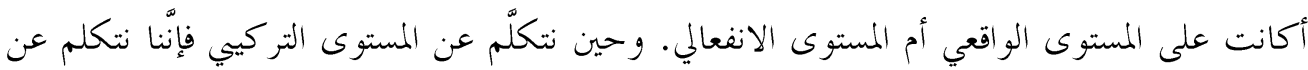

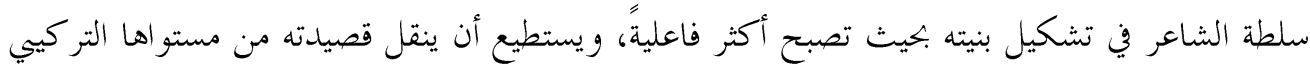

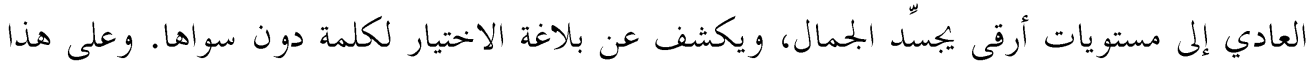
الأساس فإنهّ قيمة القصيدة تعتمد على التشكيل والتركيب وفق أسلوب إن تعبيري يختاره الشاعر، وهذا

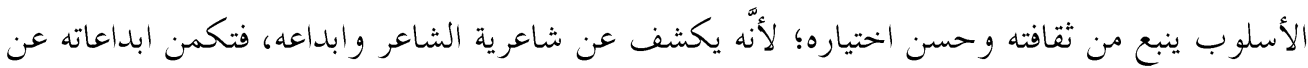
طريق اختياره لنسقِ وأسلوب القصيدة.

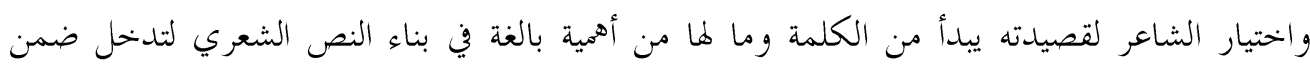
سياق له القدرة على استيعاب التجارب النفسية والشعورية كلها، ويحدث هذا (باتساق اللفظة وتو افقها

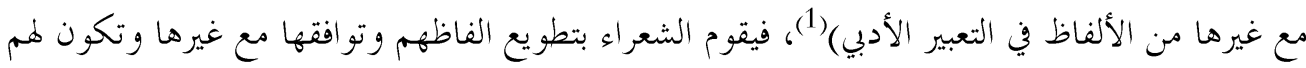

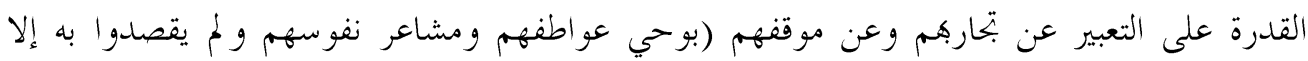

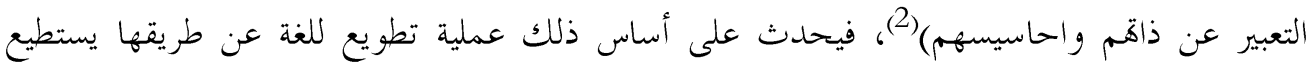

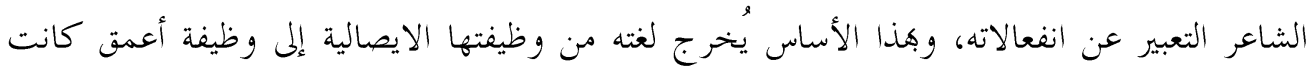

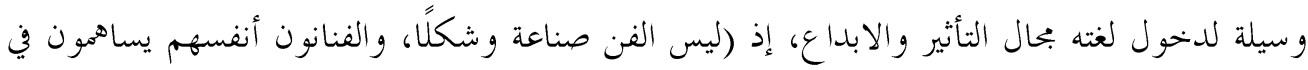

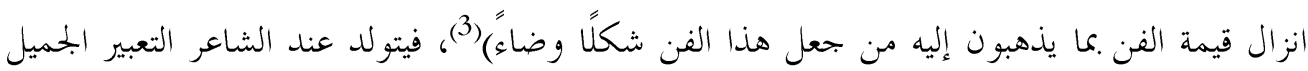

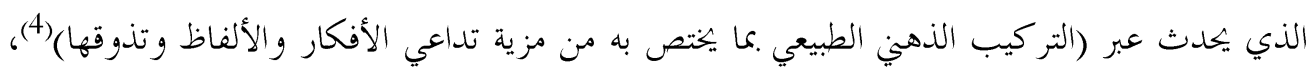
فاللغة في الشعر هي لغة تركيبية؛ لأنَّ التركيب عملية يتطلبها الشعر ليمثل نجاحًا للشاعر (5).

\section{تر كيب البيت الثعري}

إنَّ الثاعر المبدع هو الذي يجعل شعره كالقلب النابض، فيكون شعره مواكبًا لحالته وعاطفته، وهو الذي يكون قادرًا على جعل الفاظ شعره طيعة سلسة قادرة على استيعاب بتربته، فيكون الشاعر قادراً

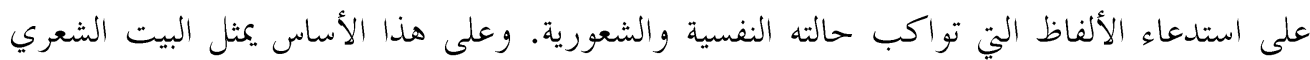

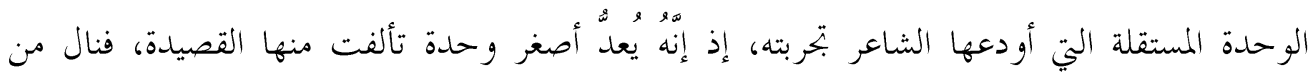

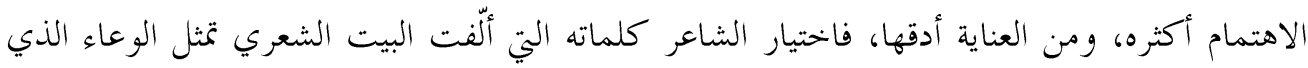


نقل معناه (في صوغ وتأليف العبارات المتواصلة التي تكون صورة مطابقة لهذا النموذج المعنوي القائم

$$
\text { بنفس الأديب)(6). }
$$

و نال البيت الشعري اهتمامًا من العرب، إذ كانوا أكثر عنايةً وأفضل اختيارًا لما يمتلكه البيت الشعري من

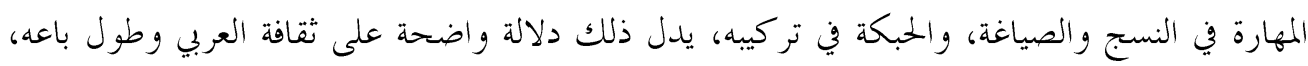

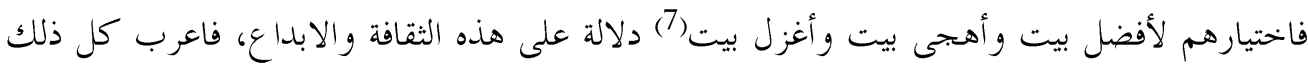

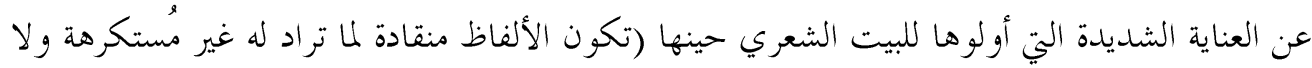

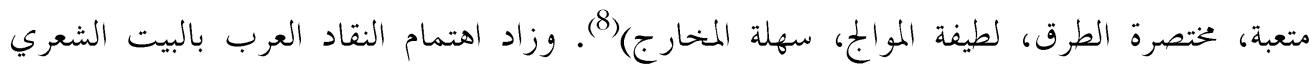

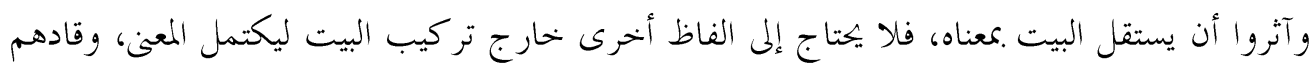

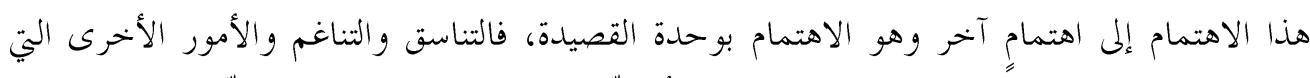

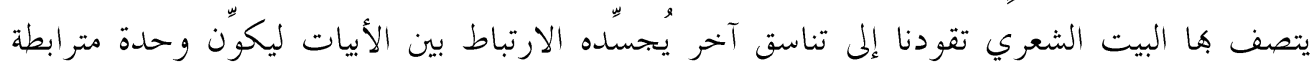

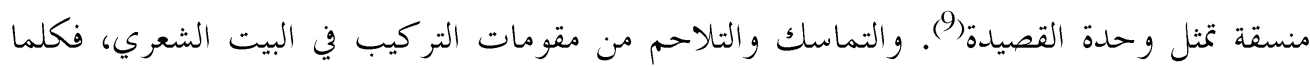

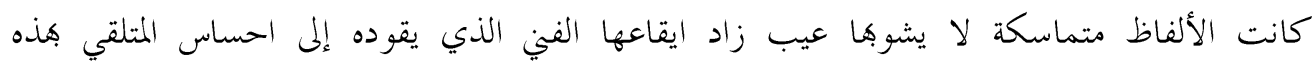
الجمالية) (10)

وعند استقراء طرق الأداء في شعر أسرة آل وهب حاولت الوقوف على عناصر عديدة تمثل أهم تقنيات

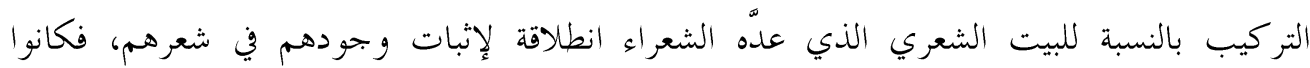

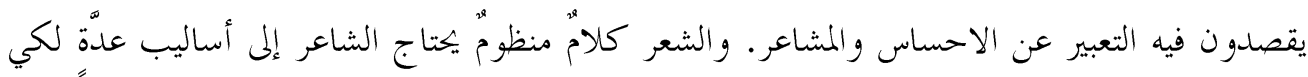
يرُكِّب بيته الشعري، وهذا التركيب من شأنه أن يفرق بينه وبين الكلام المنثور، ومن الأساليب التي

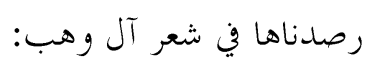

أولًا: الحخبر:

وهو الكلام المفيد المنطوق به نقرره للإخبار عن أمرٍ ما، وهو يمتمل الصدق والكذب لذاته، وهذا

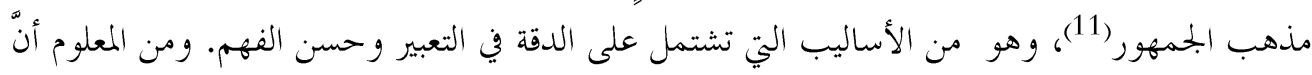

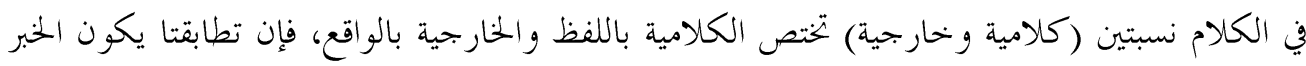
صادقًا، وإن لم تطابقا يكون الخبر كاذبًا(12).

وفي الشعر يخرج الخبر عن غرضه الأساس في افادة المُخاطب لأمرٍ قد جهله أو لازم الفائدة؛ لأنها

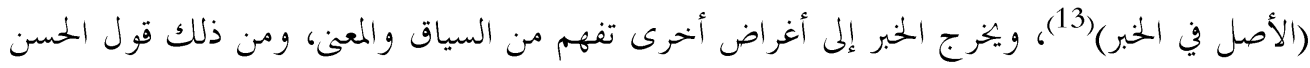
بن وهب: [الوافر] 


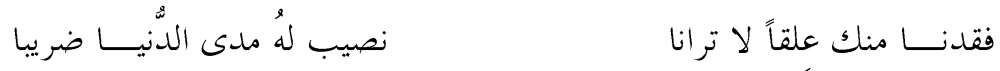

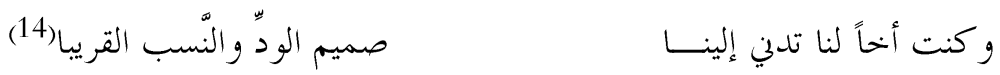

فالحسن بن وهب لمُ يُردٌ افادة المُخاطب في اخباره هذا، وإنمّا أراد أن يظهر ما في داخله من حجبة للشاعر أبي تمام، واظهار تحسره على فقدانه، فخرج الخبر هنا إلى معنى التحسر والثوق على المرثي الذي أودع في قلب الحسن مزيلًا من الحزن، ويعطي شعره دلالة واضحة على العلاقة التي كانت تربط بينهما، و الشاعر هنا كان ميَّاً إلى الصدق في شعره لذكر ما كان يتصف بـ به أبو تمام في حياته. ولا يخفى على أحد منهم النكبة التي حلَّت بسليمان بن وهب فقد نال ما نال من المتاعب، قال مخاطبًا [الحسن: [الكامل:

وستنجلي، بل لا أقول لعلَّها

ثقة به إذ كان يملك حلَّهــــ(15)

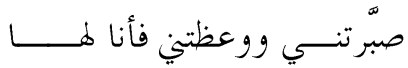
و ويحلُها من: كان صاحب عقدها

لعله احساس سليمان الداخلي وشعوره بخيبة الأمل وطول الانتظار جعله يستعطف ويسترحم مَن كان سببا في نكبته بعد يأسه من الاستجابة له باعثا شكواه و وفارقة الهم له لعله يصرف فنه عنه هذه النكبة ليرجع إلى سابق عهله في العز والوزارة، ونرى سليمان هنا فزع إلى الصبر واثقاً من أنهّ ستفرج كربته، ونرى في شعر أحمد بن سليمان ملامح الارتياح و الفرح؛ لما أودع في قلبه من استحسان للشعر، يقول:

$$
\begin{aligned}
& \text { وقر أت شعرك فاستطلت ' لحسنه }
\end{aligned}
$$

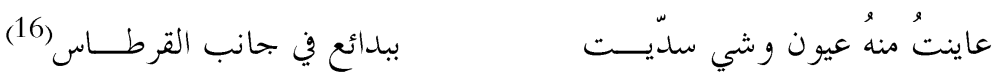

[Jامامل

رضا أحمد بن سليمان عن الشعر دليل على استحسانه له، عبه في شعره هذا بألفاظ رقيقة أبنأت عن هذا

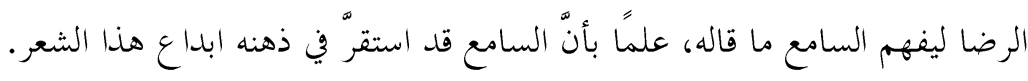
وكان الغزل من الأغراض التي خرج إليها الخبر، وذكر لوعة القلب بسبب الهجر من ذلك قول القاسم بن عبيد الله: [الكامل]
تأتي ووقت زو الها لا يأتــي
ورَن اغتدت في القلب منها لوعة
وغدت بكفِّك ميتيت وحياتي (17)

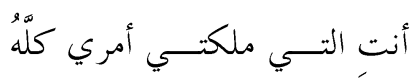


كشف لنا الشعر هنا لوعة الشاعر عن طريق ثبوت حبه لها و تغير حالها معه محا يعزٍّ لوعته وغزله، هذا يكشف عن وضعه النفسي المضطرب الذي كشفه سياق البيت الثاني، فضلًا عن استسلامه هلا، فأراد

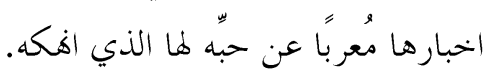

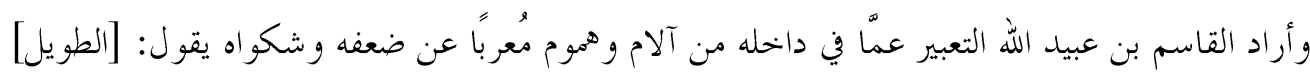

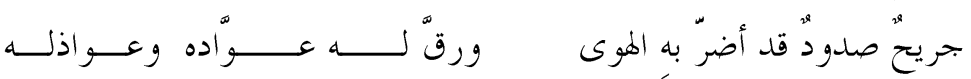

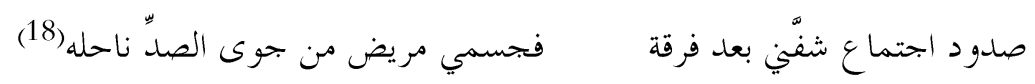
جسمَ الشاعر هنا حالة الحزن مُخبرا بها عن ضعفه وطول شكايته من صدود المحبوبة عنه حتى وصل إلى مستوى القنوط، فلا يرى ملمححًا للأمل في رجوعها، فلجأ الشاعر إلى الشكوى محا جرى له لعلَه يجد مَن

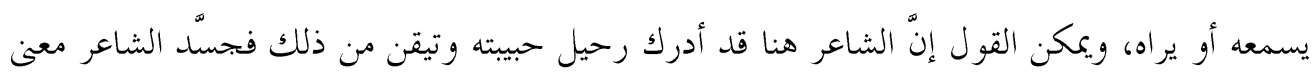
التحسر و اليأس في الفاظه، ويسعى الحسن إلى اثبات ذاته مُشيراً إلى نفسه بخبر خرجٍ و الفخر بنغسه، يقول:
فأنا ابن وهب ذو السماحة و النّدا(19)
أنا ذا فإن لم تعرفيني بعد ذا لران

خررج الخبر هنا إلى معنى الملدح والفخر، فخرَّ الشاعر بنفسه ليثبت لمحبوبته أنهَ ذو صدى واسع في أبناء قومه، وما يمكن استنتاجه من دلالة إنَّ الشاعر هنا لم يفخر بنفسه فحسب، وإنماّما فخر بقومه؛ لأنها بمثابة تسجيل تاريخ لقومه، عبّر بألفاظ نسبها إليه. و في الخبر يمكن مراعاة أحو ال المُخاطَين، و كيف يمكن للمتكلم أن يلقى الخبر، فإذا كان المُخاطَب نحالي

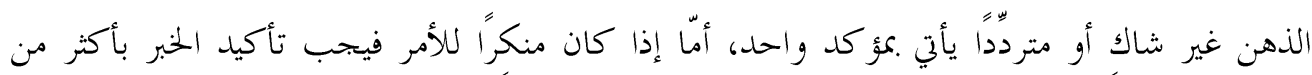

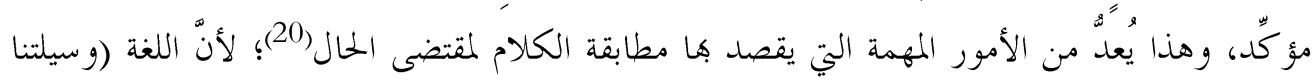

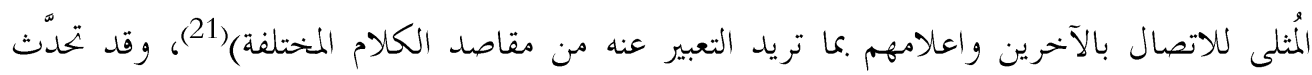

$$
\begin{aligned}
& \text { الحسن بن وهب عن الفر اق بقوله: [الكامل] }
\end{aligned}
$$

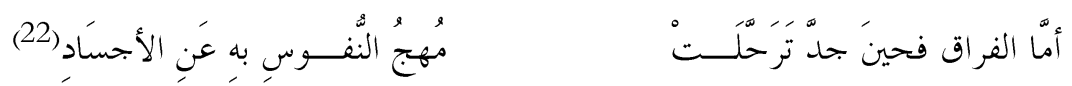

فقول الحسن (ترحلت مهج النفوس عن الأجساد) خبر ألقاه من غير مؤكدات، فلا حاجة له إلى تأكيده تبعًا لطبيعة النفس الإنسانية، إذ إنها تلقَّت الخبر من غير علم بتصديقه وتكذيبه، وفي البيت بتحسيد لحالة اليأس بعد معاناة أمله في الرجوع، فعندما ثبت له عكس ذلك لم يعد يعقد أملًا مرةً أخرى؛ لأنَّ نصيبه كَّن يحب بلدأ بالانتهاء. 
وقد أدخل الحسن بن وهب على شعره أداة تو كيد؛ لأنّ المخاطَب كان شاكَّا متردةًا في أمره في قوله:

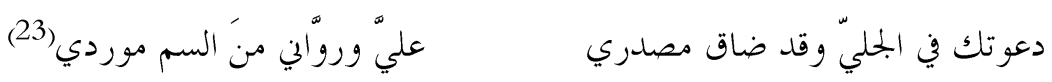

[الطويل]

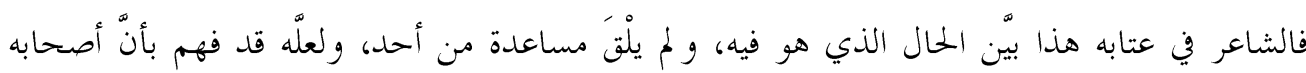

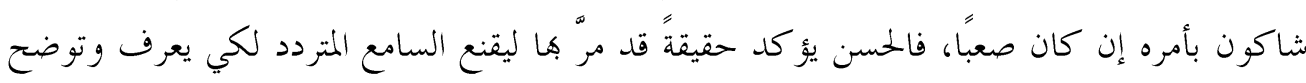

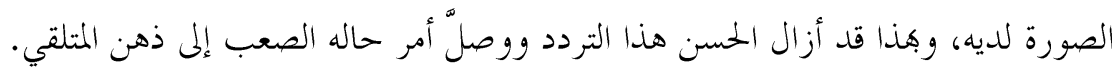

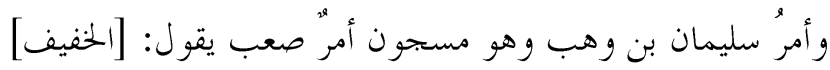

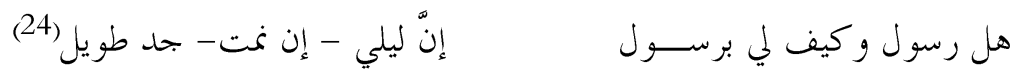

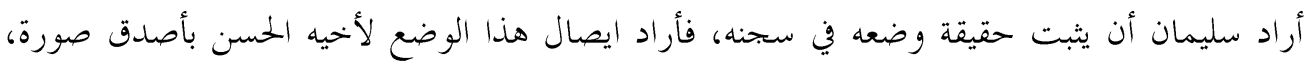

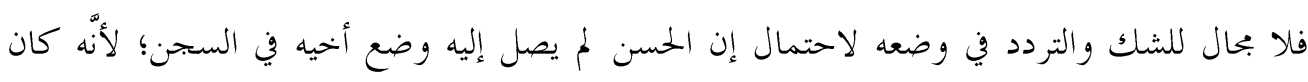

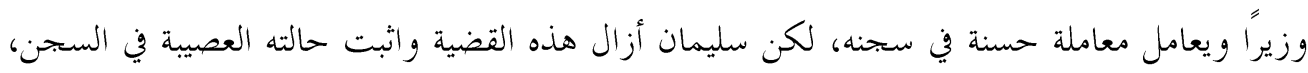

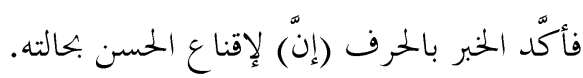

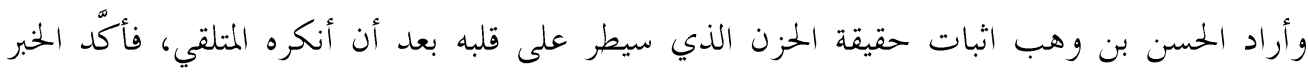

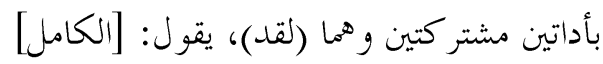

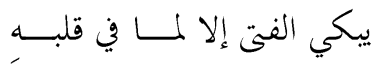

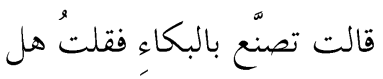

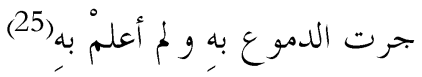

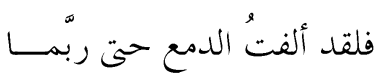

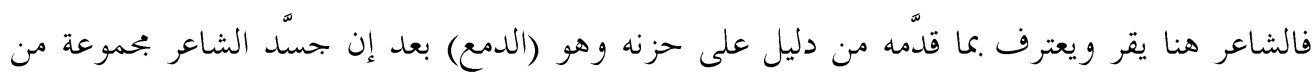

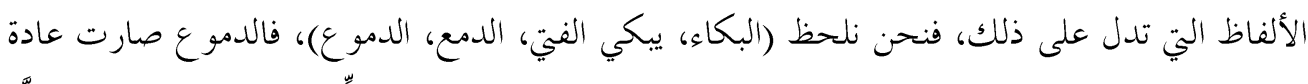

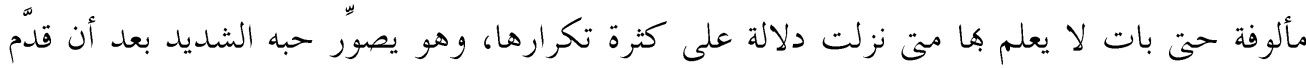

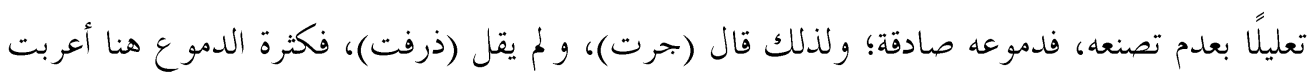
عن تجربة عاطفية مريرة حتى أصبح الدمع عنده عادة.

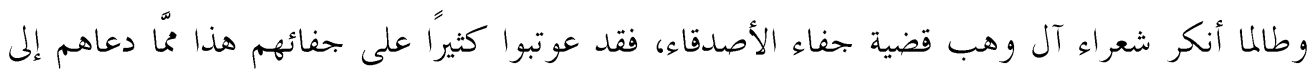

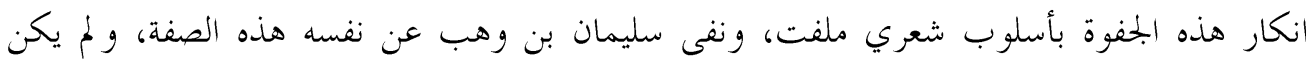

$$
\text { الجفاء من شيمته أو خصاله أو أخلاقه فيقول: [الطويل] }
$$


لم يقبل سليمان هذذا الأمر، فحاول انكار ما قُدّمّ له مستعملًا أداتين هما (إنَ، ولام التو كيد) لإنكار الخبر

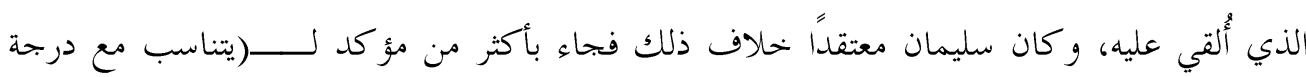
انكاره له، لإزالة هذا الانكار)(27). وفي المعنى نفسه نرى الحسين بن محمد بن القاسم (البارع) ينكر ادّعاء ابن الهبارية حينما عاتبه على لهاري الجفاء، يقول: [الخفيف]

\author{
مكلام يكـاد يحرق جلدي.

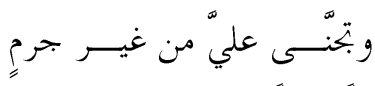

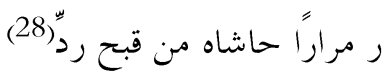

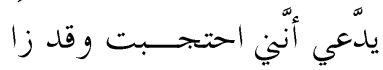

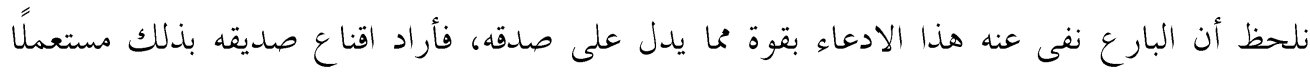

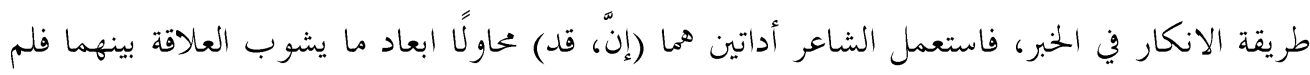

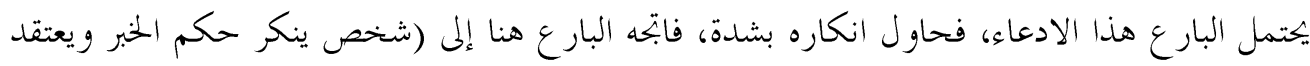
فيما يخالفه؛ لذلك كان من الواجب تأكيد الخبر له على حسب الخدار انكاره)(29).

ثانيًا: التقديم والتأخير:

وهو من الأبواب المهمة في اللغة العربية، فيه دلالة على مرونة اللغة وشموليتها، وله من الأهمية الدلالية

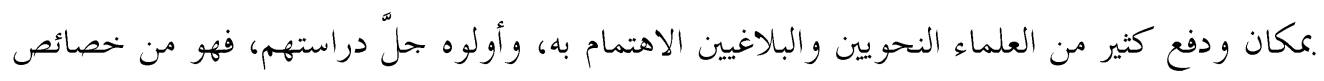

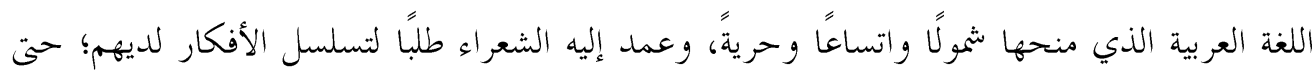

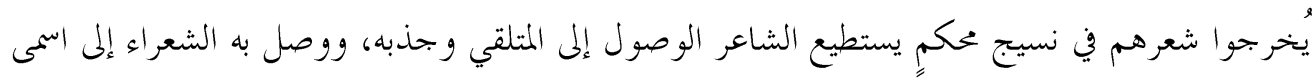

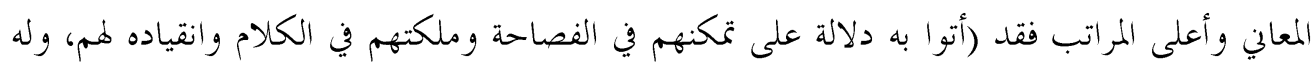

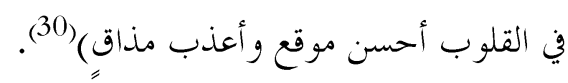

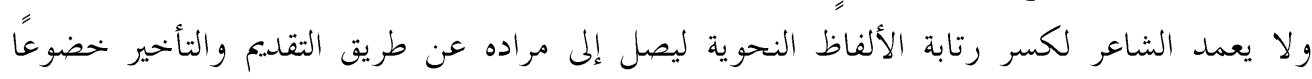

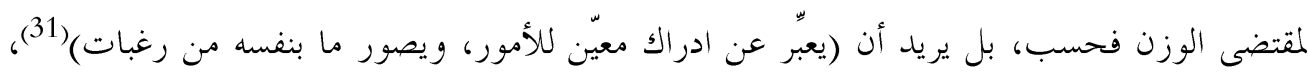

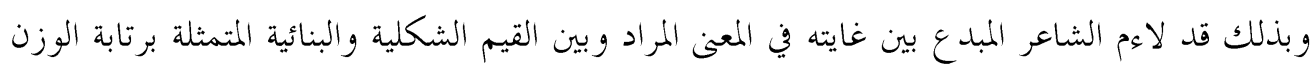
الشعري وسلامته.

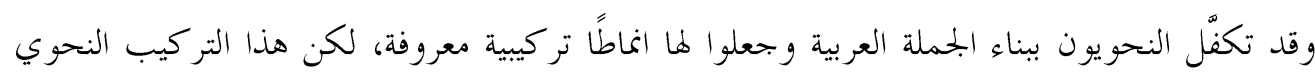

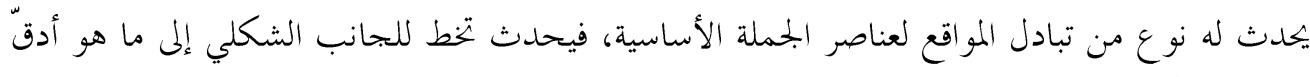

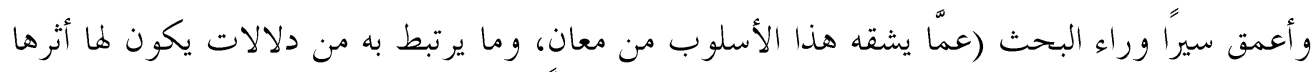
في فنية التعبير وجماله)(32). 
ومن أكثر البلاغيين اهتمامًا بموضوع التقديم والتأخير هو عبد القاهر الجرجاني الذي أو لاه أهمية لإدراكه

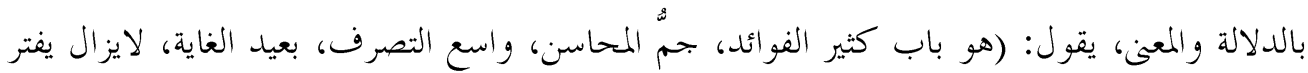

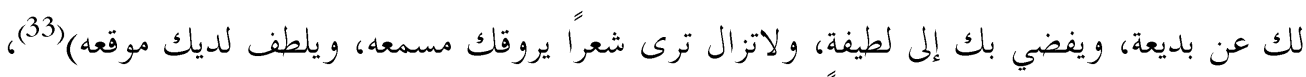

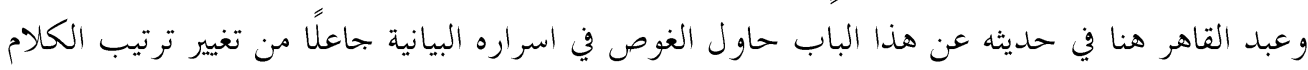
اللفظي يفضي إلى انتاج ترتيب ذهني يخدم المعنى. وعند تتبع شعر أسرة آل وهب بند في شعرهم هذا الأسلوب له فو ائد كثيرة، إذ إنهّم في هذا الأسلوب اعطو المعنى رعاية خاصة، فجاء التقلديم والتأخير في شعرهم على النحو الآتي:

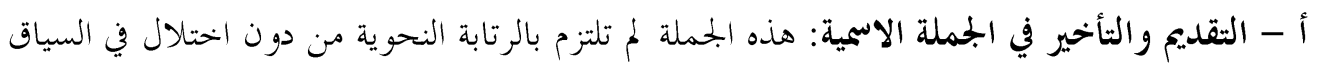

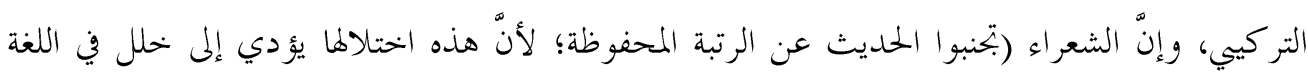

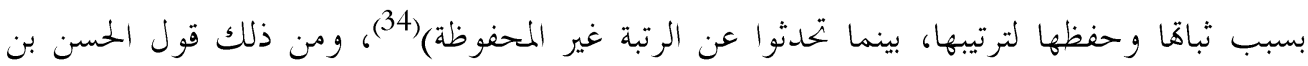
وهب: [الطويل]
كم نفس من أهدى الشفانين عامدا شفاء أنين بالشفانيــن أمّلت

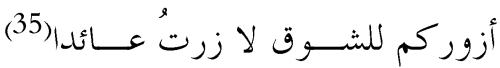 كلوها يكلَّ الداء عنكم فإنيّني

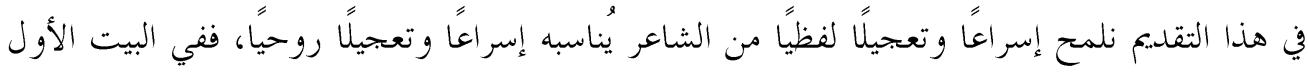

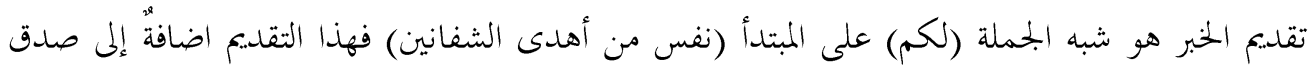

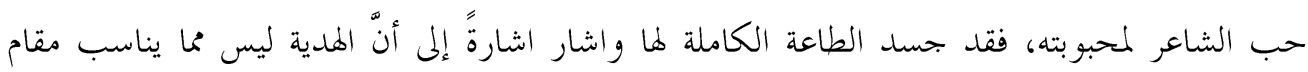
الحبيبة، فنرى منه ذلك الانقياد اطلقه الشاعر من موقع عذبٍ افصحت عنه بحموع الألفاظ كلها،

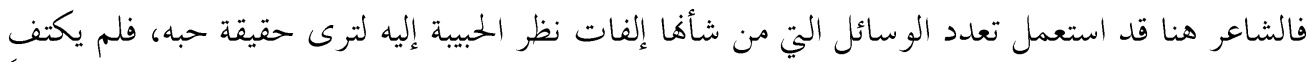

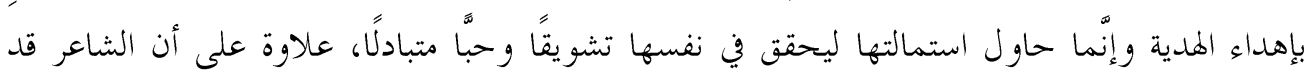
أكَّد حبه لها، فالهدية باب للمححبة، وتقديم النفس أبواب الماب المحبة كلها.

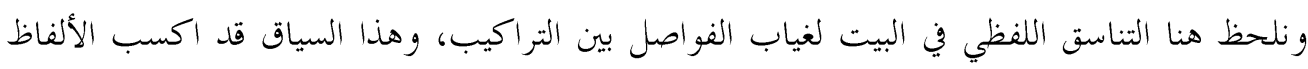

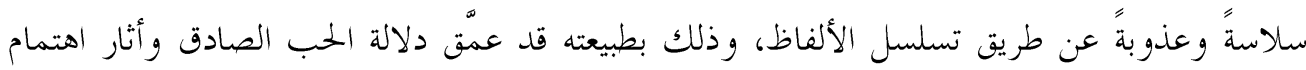
الطرف الثاني لفهمه بأحادية حبه هلا، فلو قال (نفس من أهدى الشفانين لكم) لبقت الحبيبة شاكة في ودئ

$$
\begin{aligned}
& \text { حبه من أنَّهُ قصدها وقصد غيرها، وأشار الحسن إلى صفة من صفاته بقوله: [الطويل] }
\end{aligned}
$$

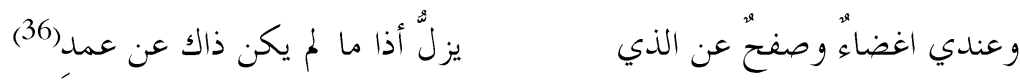


في البيت تقدهّم الخبر (عندي) على المبتدأ النكرة (اغضاء) وهذا ما تدلُّ عليه القاعدة النحوية في علدم جواز الابتداء بالنكرة دون مسوغات بتيز ذلك(37)، وهذا من شأنه أن يكشف عن القدرة اللغوية

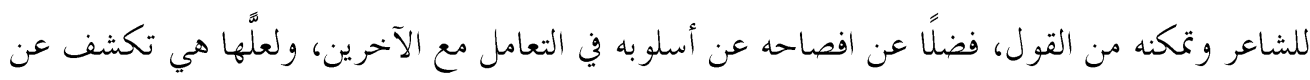
طبعه غير المكتسب في التعامل، والشاعر هنا رسم له موقفا قد أظهر فيه تعاطفه ومساحته، ملدركًا بأنه قد حكىم على نفسه معبرًا عن شعوره الصادق ازاء مثل هكذا مواقف، وربهما أراد الشاعر هنا إرسال رسالة إلى الخليفة أو الأمير يطلب منهم الصفح والعفو عن الذين أصابتهم النكبة في السجن. و نرى الخسن في موقف آخر؛ يلجأ إلى الدعاء لأنهّهُ خير وسيلة يكفكف هها دموعه، يقول: [الكامل]

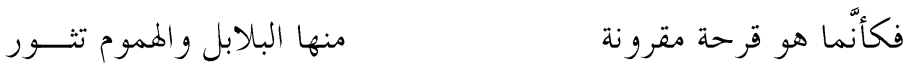

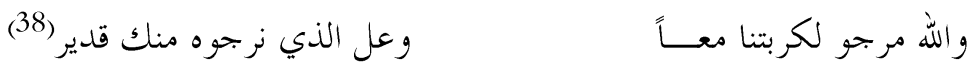

قاهّم الشاعر الخبرَّ (على الذي نرجوه) على المبتدأ (قدير) و كان ذلك فيه دورّ للشاعر في رصد قافيته، فضلًا عن الملاعمة البنائية نلاحظ حرص الشاعر على تأدية معاني الهم والحزن بأسلوب فيه كثير من الإثارة، وقد لا تتحقق بأسلوب غيره، و بعد أن أفصح الشاعر عن اساه وحزنه التجأ إلى الدعاء راجياً من الله أن يحقق له خحلاصه من محنته بعد أن لاقى من الصدود ما لاقاه واستقرّ في ذهنه قدرة الله على

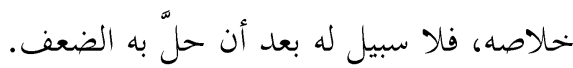

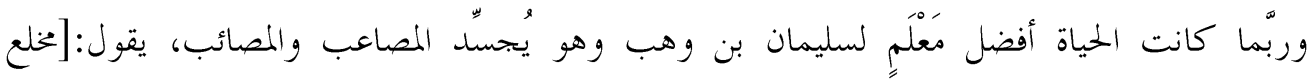

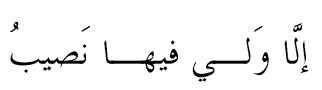

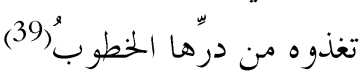

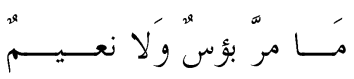

$$
\begin{aligned}
& \text { كذاك مَن صاحب الليالــي }
\end{aligned}
$$

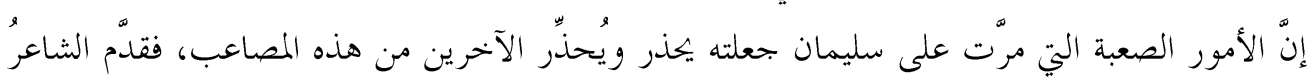
الخبرَ (لي) على المبتدأ (نصيب) لتتجلى لنا المبالغة في القول، أظهر لنا الشاعر بهذا مدى قوة صعوبة الحياة

$$
\text { لديه، فكانت مصائبها عليه كثيرة. }
$$

ونلحظ هنا أنَّ الشاعر تكلم عن البؤس أولًا مؤجلًا الحديث عن النعيم، ربهما كان نعيمه ظاهرً آلكلٍ أحد، فغيره في تركيب الألفاظ لغاية دلالية مراده منها افهام السامع بحاله؛ وذلك لأنّ الدلالة التي

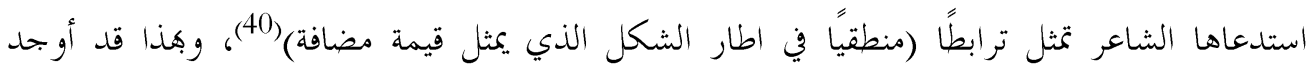
الشاعر علاقة تخصيص بين الاداء التعبيري والقيمة الدلالية التي أبانت أسلو به الحياتي. 
وقد رقّ الشاعر الحسين بن محمد بن القاسم (البارع) في شعره حتى بدا لقارئه أنهّ يمثل نوع من الغنائية في الفاظه السهلة الرقيقة، يقول: [المديد]

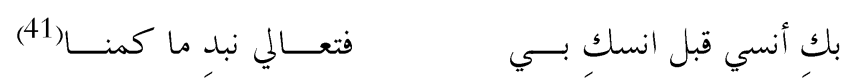

قدَّم الشاعرُ الخبرَ (بك) على المبتدأ المعرفة (أنسي) قاصداً التخصيص والتشويق بعد أن زاد هيامه بها

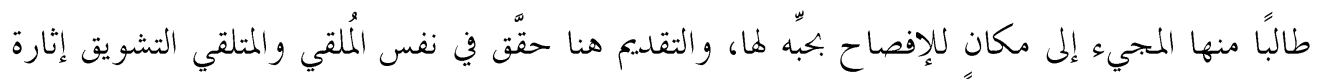
المتعة و الحبب، فأنسه وارتياحه غختصة بها فلا يجل ميلا إلى غيرها. و نلحظ هنا التناسب الموسيقي الذي وظّفه الشاعر ليجد لنا مناسبة ايقاعية بين تركيب فيه تقديم و تأخير وآخر مشابه له قادنا ذلك إلى فهم نوع من تغير الدلالة؛ وذلك لأنَّ (أي تغيير في النظام التركيبي للجملة يترتب عليه بالضرورة تغيير الدلالة وانتقالها من مستوى إلى مستوى آخر)(42).

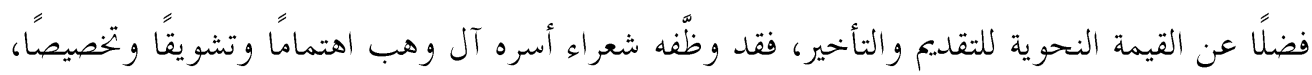

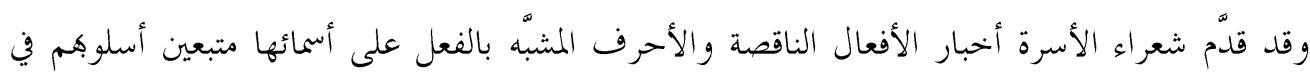

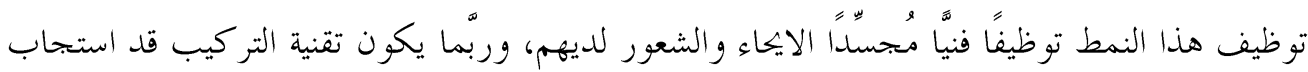

$$
\begin{aligned}
& \text { ها الشعراء لأوزاهم و تفعيلاتهم وقوافيهم، من ذلك قول الحسن بن وهب: [الطويل] }
\end{aligned}
$$

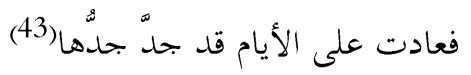

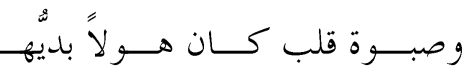

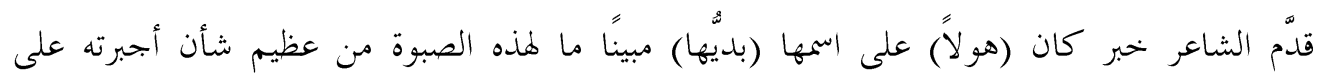
الإفصاح بآلامه قاصداً تودده للمحبو بة طالبًا منها التقرب و والمحبة.

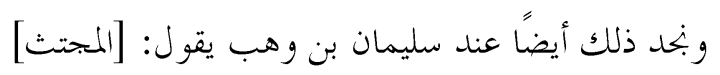

$$
\begin{aligned}
& \text { جوى هو اه خلاص } \\
& \text { وأبصرتين رخهــاص }
\end{aligned}
$$

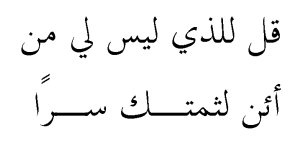

معبراً عن حبه الذي رسم له حالة مأساوية بجلت في صدو دها عنه، فأفصح لها بأنّ حبها ثابت في قلبه متشوقا لما فهي حاضرة في ذهنه، فلا يقدر على نسيانيها بحسداً في شعره هذا مضموناً عاطفيًا نراه يتلذذ في ذكره مكرراً له .كجالسه.

ب: التقديم والتأخير في الجملة الفعلية: وهذا المظهر يتقدم فيه المفعول به على الفاعل اهتمامًا بالمفعول

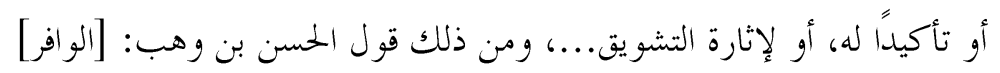

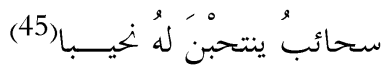

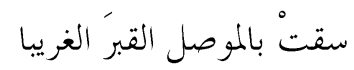


عمد الحسن إلى تقديم المفعول به (القبر) على الفاعل (سحائبُ) دلالة على تأكيد حزنه على صاحب

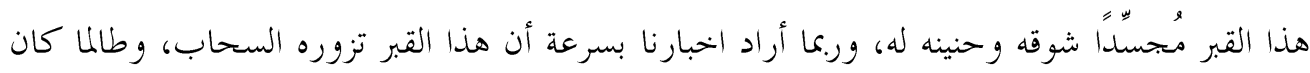

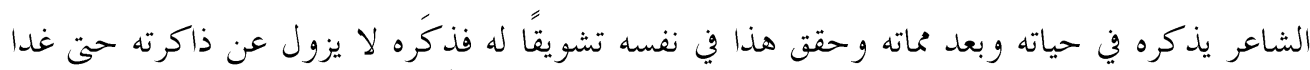

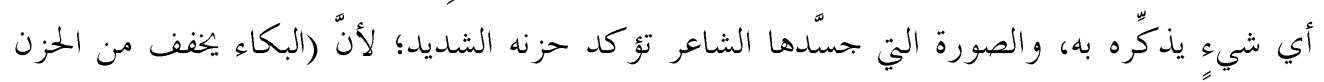

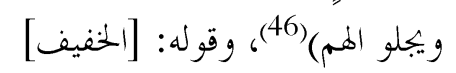

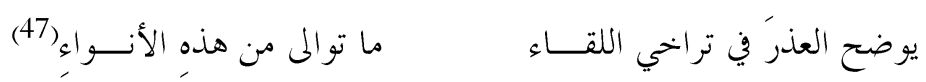

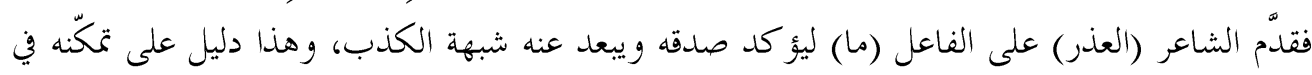

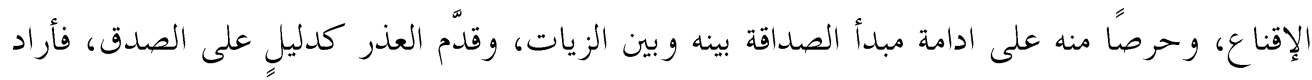

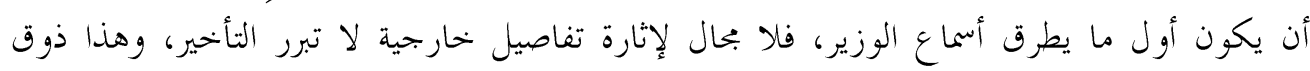

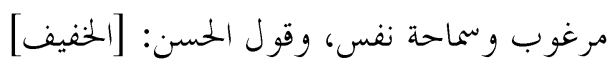

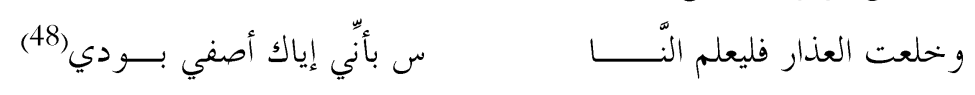

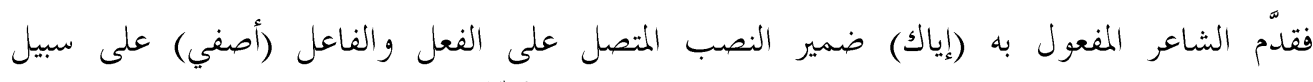

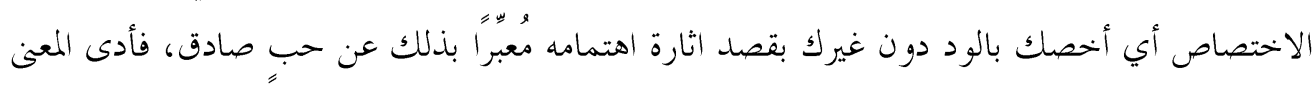

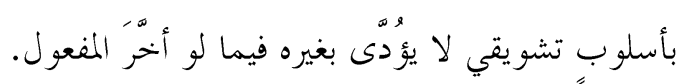
وشبيه ذلك قول سليمان بن وهب: [الرمل]

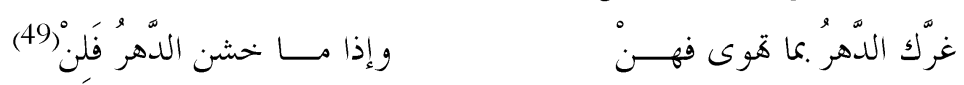

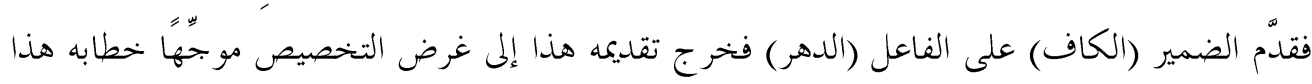

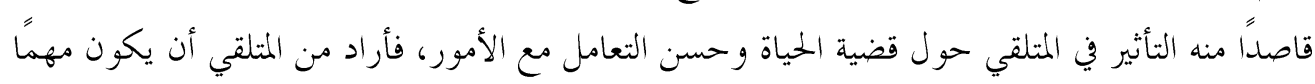
أكثر.

$$
\begin{aligned}
& \text { ورسخ هذا الأسلوب في شعر الحسين بن محمد بن القاسم (البارع): [لمتقارب] }
\end{aligned}
$$

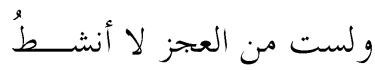

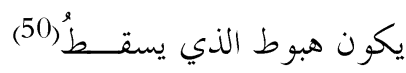

$$
\begin{aligned}
& \text { تنازعني النّفس "أعلى مقـــــــامِ } \\
& \text { ولكن بقدر علو المككـــــــــــان }
\end{aligned}
$$

قدمّ الضمير (الياء) في (تنازعني) الذي هو مفعول به على الفاعل (النفس) إشارة من الشاعر على اثبات

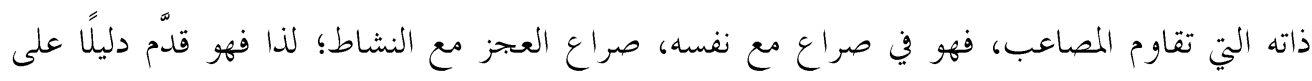

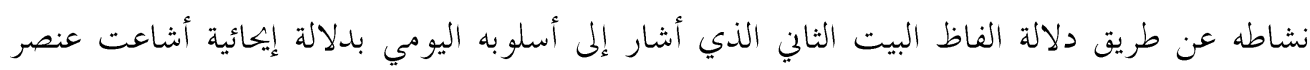
اثبات الذات أو اعلاءً من الشأن. نئ. 
ثالثًا: الحذف:

هو من المسائل المهمة التي أولاها البلاغيون اهتمامهم؛ لما يحدثه من توافت ين منتج النص وسامعه، فيعدٌّ

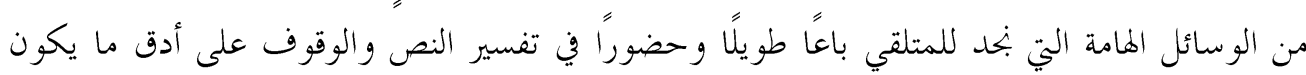
عليه، فهو (باب" دقيق المسلك، لطيف المأخذ، عجيب الأمر، شبيه بالسحر، فإنكّك ترى به ترك الك الذكر أفصح من الذكر، والصمت عن الإفادة أزيد للإفادة، و بتحدك أنطق ما تكون إذا لم تنطق، وأتم ما تكون بيانًا إذا لمُ تَنْ) (51)

والحذف من الوسائل التي تعطي النص الشعري سمة من سمات العلو والرفعة الذي يقود الشاعر إلى ابداعه في القول؛ لأنه (من دقائق اللغة، وعجيب سرها، وبلديع اساليبها، إنَّك قد ترى الجمال و الروعة تتجلى

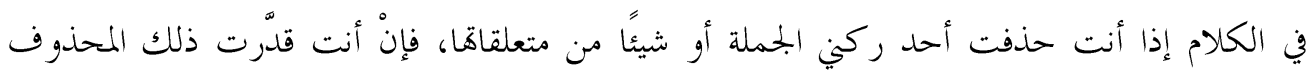
وأبرزته صار الككام إلى غثثٍ سفساف) (52). وأسلوب الحذف يصبّ في صلب ابداع الشاعر، فالحذف له أسراره وقضاياه، فلا يهذف لفظ من الكلام المبدع إلا لغاية مما فتح المجال أمام المتلقي للبحث العميق والغوص في أغوار النص لكشف حقيقته و بيان جمال أسلوب منشئه(53)؛ لأنّ القارئ يجلد متعة في النص عند استكناه سياقه، فلا يحدث ذلك إلا بكشف أسرار النص والوقوف على ايهاءاته، ولا يمكن أن تراعى القواعد المنضبطة عندما

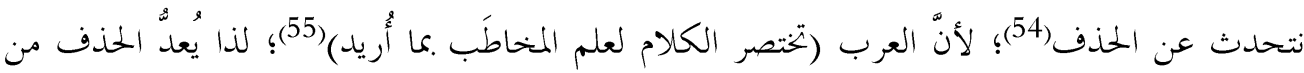
الأمور البلاغية المهمة التي تتفق مع الفطرة الإنسانية التي تميل إلى الاختصار، وتسعى إلى تقليل الجههد.

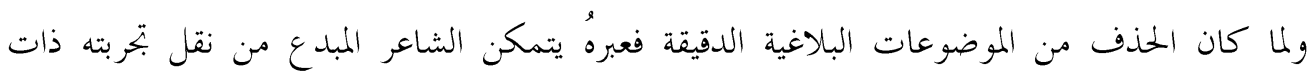
الدلالات المعنوية الموحية والكثيرة، والمعاني الملفتة بألفاظ قليلة دلّت على القابلية الفنية في رسم صورة

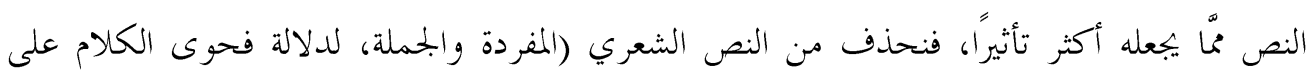
المحذو ف، و لا يكون إلا فيما زاد معناه على لفظه)(56). ولا كان الحذف يمتلك من الأهمية التي أشرنا إليها فقد وضع له البلاغيون شروطًا(57)، جعلته وسيلة من و سائل الشاعر في فيض ابداعه، واعطاء النص جانبا من الرمزية والإيهائية ليجد قارئه لذة فنية لا يجلدها في النصوص التقريرية الواضحة، كونه سيكون مشاركًا في انتاج المعنى، وبذلك يكون النص الشعري له القدرة على التأثير. لقد حقّ أسلوب الحذف عضلف حضورًا في شعر أسرة آل وهب، وجاء في أغراض شعرهم لغاية معنوية أكسبت شعرهم نوعًا من التميز توخاها الشعراء في نصوصهم، من ذلك قول الحسن بن وهب: [الهزج] 


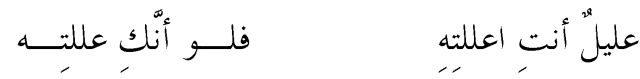

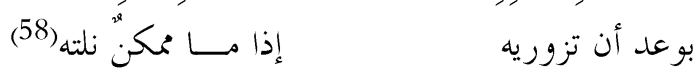

حذف الشاعر المسند إليه (هو) وأبقى المسند (عليل) قصد الشاعر هنا اظهار صفة الألم والمرض الذي تروي أصابه بسبب غياب الاهتمام من حبيته، وهو بذلك أراد من حبيته الوقوف على أمره هذا والدراية به لتستيقن من ذلك، فقدمّ شرحًا لحالته بأقصر الطرق. و في حذف الشاعر دلالتان الأولى معنوية فالشاعر حذف ليظهر ذاته، فلفظ المسند هنا أصبح ذات الشاعر مصاحبً له وليس صفة" تزول بزوال السبب، والدلالة الأخرى دلالة فنية فَحَذفهُ للمسند إليه قد رصد التفعيلة الأولى في الشطر الأول ليكون البيت أكثر رتابة له من الايقاع الموسيقي ما يشدُّ الانتباه و سرعة احضار ذهن حبيبته إليه دون اطالة في كلامه، واشارة الشاعر إلى حبيبته وجعلها سببا للعلة (أنت اعللته) فيها وصف للحظة الثدة والضيق يقابلها ضعف الشاعر، ساعده ذلك في تصوير موقفه(59). ونلحظ الحالة المأساوية التي مرّها هِا القاسم بن عبيد الله جعلته يطلق عنان الحديث مترحمًا على نفسه،

$$
\begin{aligned}
& \text { بقوله: [الطويل] } \\
& \text { تخوّنه من آجل البين عاجله } \\
& \text { كئبب حزين وُّ واكف الدهمع هامله }
\end{aligned}
$$

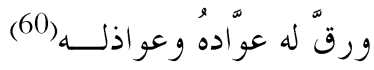

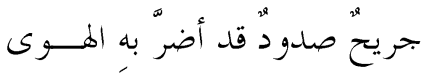

وإنَّ الشكوى هنا قد ارتدت ثوب اليأس محا أتعب الشاعر وقربه مُ من الهلاك، فجعله ذلك يباشر بسرد أوصافه التي دلت دلالة على أن الشاعر بعيد كل البعد عن أملٍ قريب، فحذف الشاعر المسند إليه (هو ) وباشر بذكر المسند الذي هو بحموعة من الأوصاف التي تكشف عن الحالة الوجدانية للشاعر التي من

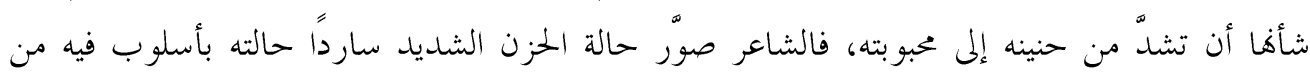

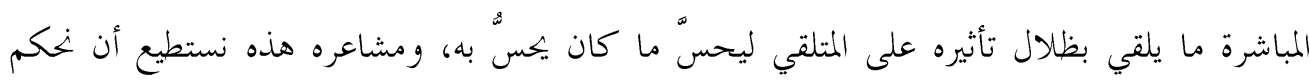
عليها بأنها مشاعر ليست طارئة، ولا تمتلك صفة التنقل والزوال بل هي مشاعر اثبتت وجودها وديكومتها فأصبحت ذاتًا قائمة تمس شغاف القلب وتعرب عن قصة عشق حقيقية رام هها الشاعر حبال الوصل فلم ينلْها، وطابع شعره هنا أفصح عن جانب قصصي تظهر فيه (الأفكار والأحاسيس صورًا تحليلية للموقف، ينمو الموقف بنمائها، وتظهر وحدها في ظلاله) (61). ويكون الحذف في شعر الحسن للتخفيف في الكالام فذكر المحذوف لا يؤدي إلى زيادة المعنى بل يزيد من عبء الكالام، فدلَّ الحذف على الاختصار بقوله: [السريع] 

مني يمينــي هات باليسرى
ما لي وللخمر وقد أرعشت

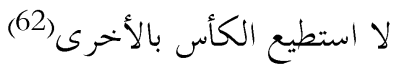
حتــى ترانـــي مائلاً مسنداً

فقد حذف (الكأس) من قوله (هات باليسرى) وتقدير الكالام (هات الكأس باليسرى)، و كذلك في بالكائ

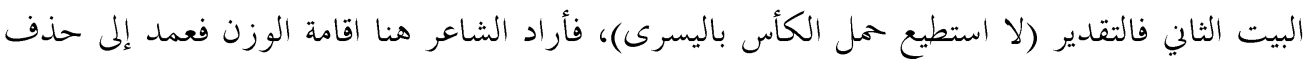

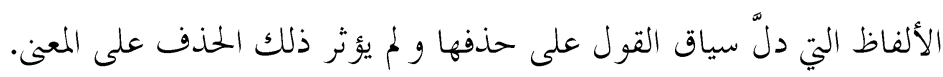

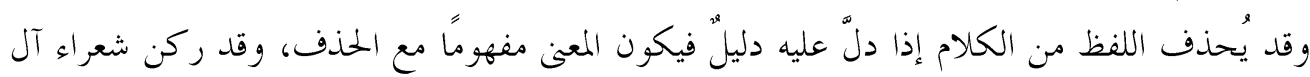

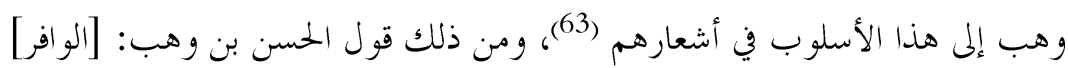

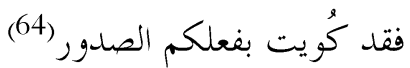

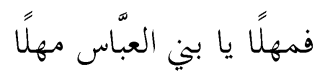

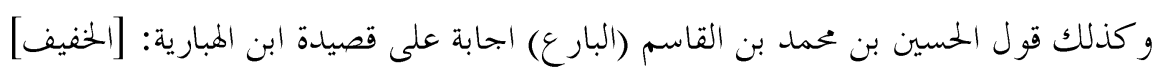

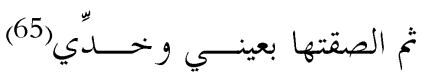

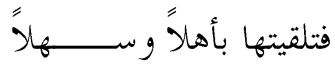

فالألفاظ لدى الشاعر في الشاهدين (مهلاً) (وأهلاً وسهلاً) منصوبة بعامل محذوف وفئل وتقدير الكلام (أمهل

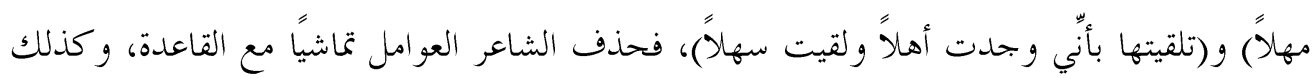

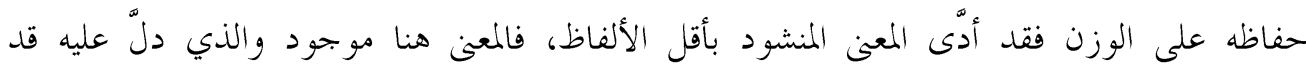
حُذف (66)، فإسهام الشاعر في اعادة التشكيل لألفاظه فيه دلالة على ابداعه وصنعته. وكانت لحذف بعض الألفاظ في شعرهم مستويات تتراوح بين البساطة والعمق، نلحظ البساطة في

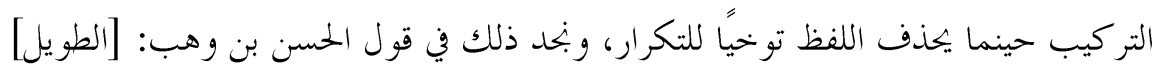

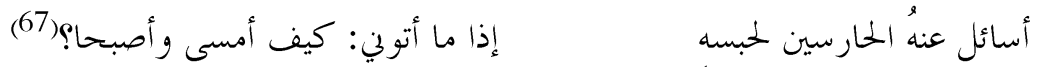

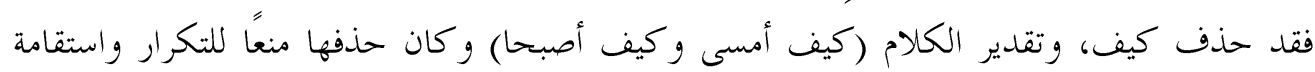
للوزن الشعري، ومثله قوله: [الكامل] ليكاد من شوق إليــك يطير (68)

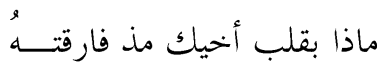
فحذف الفاعل من الفعل (يطير) لدلالة لفظة القلب في البيت.

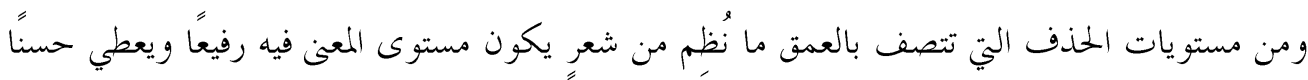

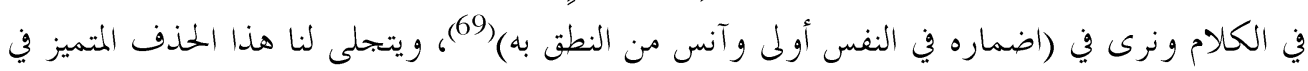

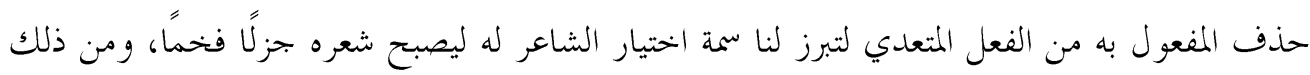

$$
\text { قول محمد القاسم بن عبيد الله: [المتقارب]] }
$$


فالفعل (ساعد) متعدٍ حذف الشاعر المفعول به ليجسبّد المعنى واضفاء صفة العمو معلى البيت، فالمساعدة

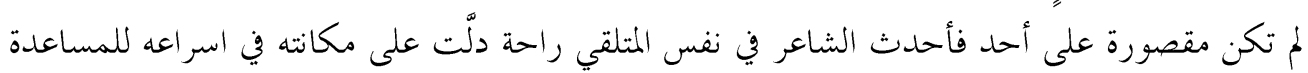
لأيِّ شخص كان.

ومن ذلك ما بنده في شعر الحسين بن محمد (البارع) إذ يقول: [المجتث] الفتى زماناً و يصفــي (71)

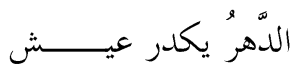

و التقدير (ويصفى عيشه) حذفه الشاعر، ومراده من ذلك اثبات هذه الحقيقة على سبيل النصح والارشاد.

ومن أنواع الحذف في شعرهم حذف الحرف من الكلام؛ لغايات فنية استوجبها الكلام، فحذقت (ياء النداء) من قول الحسن بن وهب: [اعب الوافئ لقينا بعـــك العجب العجيبا(72)

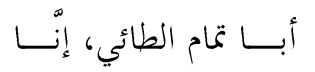

و الغاية الاختصار؛ لأنّ الشاعر في حسرة وضيق لا يقوى على الكلام، وهذا مألوف في شعر آل آل الكائ وهب(73) ومن الحروف الأخرى المحذوفة التي استوجبها الحفاظ على الوزن حذف همزة (الفداء) من قول الحسن بن وهب: الكامل]

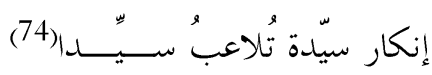
أنكرت معرفتي - جعلتُ لك الفدا ومن الحروف المحذوفة أيضًا حذف هل الاستفهامية وهمزة الاستفهام، فاستغني عنها الشعراء لوجودها في المعطوف عليهما كقول الحسن: [الكامل] أو تصدقين من المواعد موعدا(75)

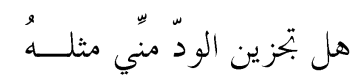

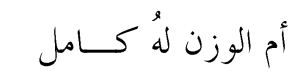
أم الوعد به حاصل (76) ألوزن كانهل وقول سليمان بن وهب: [اهزج] وفي الأسلاف تِنقيص ومن نماذج الحذف في الحروف (حذف الف ما الاستفهامية) إذا دخل عليها حرف الجر كقول الحسين بن محمد بن القاسم: [الكامل]

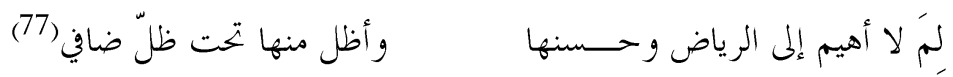

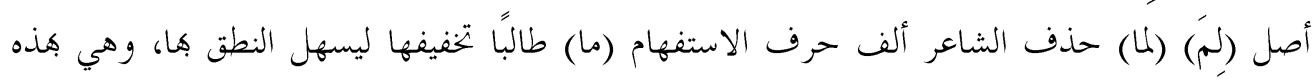

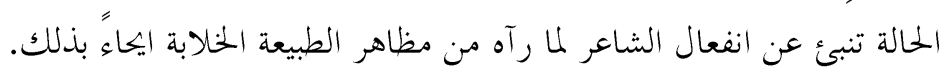


ومن أنواع الحذف الترخيم وهو حذف آخر الكلمة في النداء كقول الحسين بن محمد بن القاسم [البارع): [المديد)

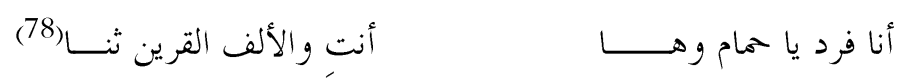

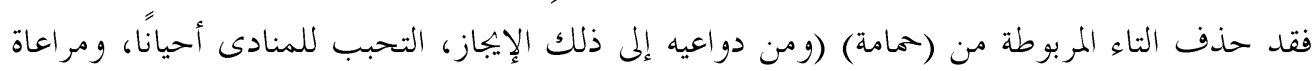
جمال فني في نسق الكلام وايثار اللفظ الأخف على اللسان إلى غير ذلك)(79).

\section{رابعا: الاستفهام:}

من الأساليب الطلبية التي استعملها شعراء أسرة آل وهب استجابة لانفعالاقم ومواقفهم في الحياة

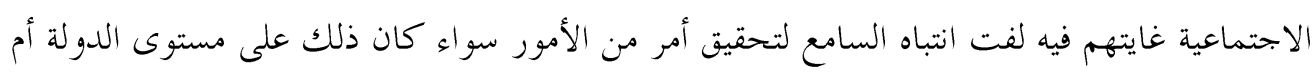

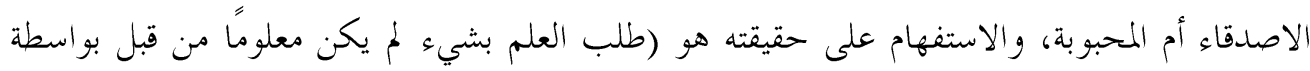

$$
\text { واحدة من أدواته)(80). }
$$

و نلحظ الاستفهام على حقيقته في قول سليمان بن وهب: [ادزه

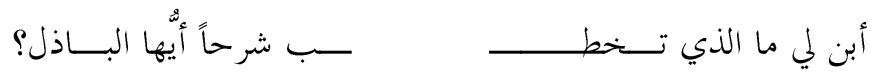

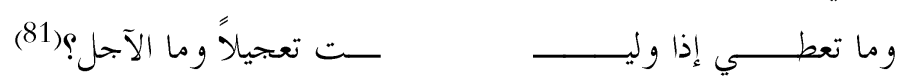

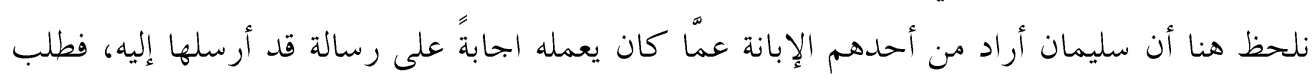

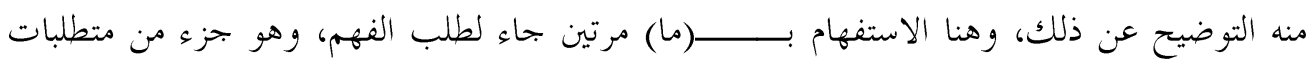
الوزارة التي يبتغي منها التوضيح.

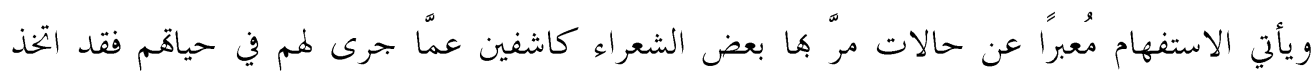

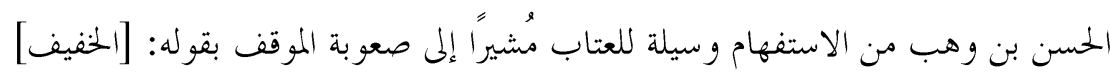

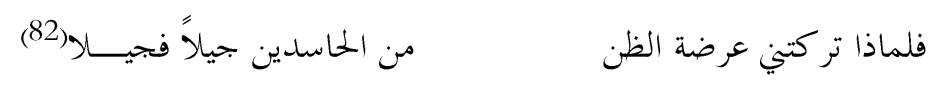

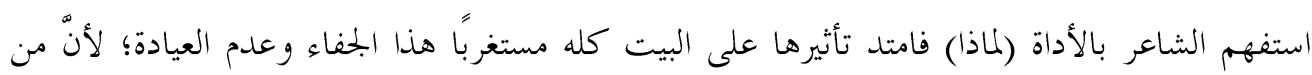

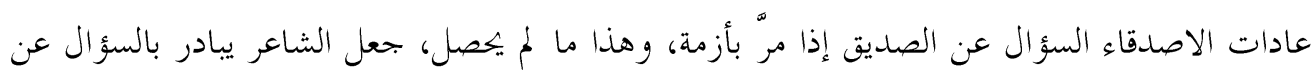

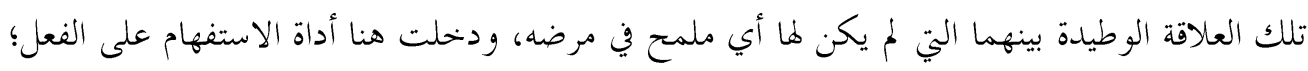

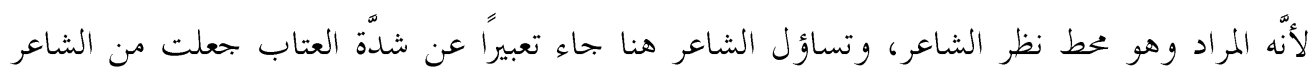

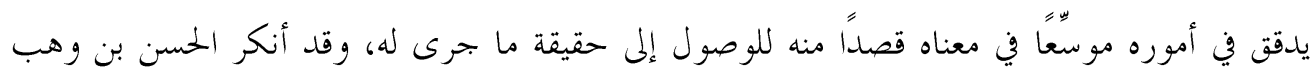

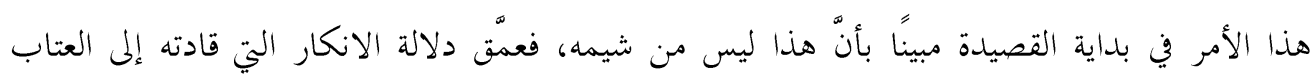
بقوله: [الخفيف] 


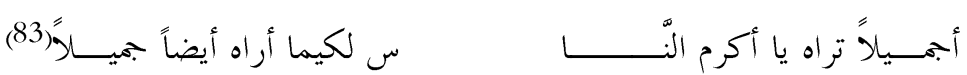

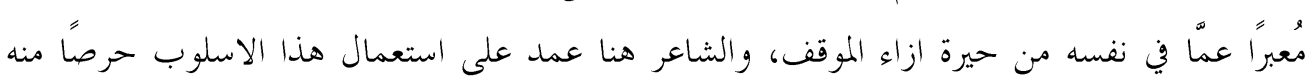
على اثارة انتباه السامع له ليجعله ادعى للتفكير في الجو انب دون افشاء ذلك له(84).

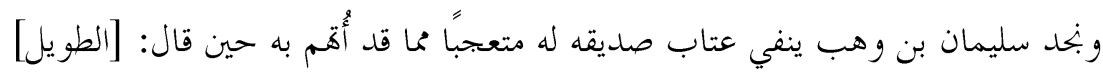
فكيف بخلٍ لي أضن بـــوده

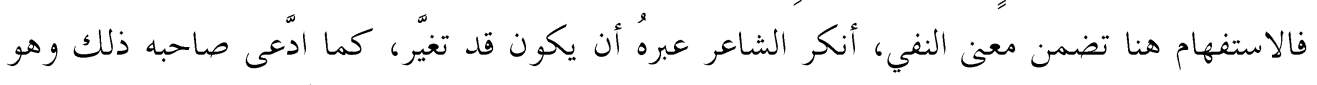

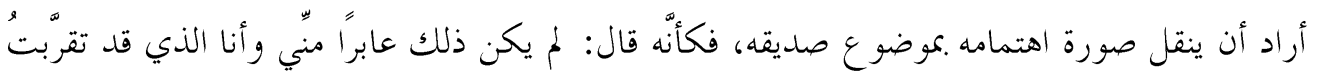

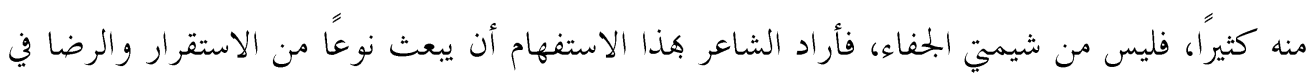
قلب السامع.

و من انكار العتاب ما نراه عند الحسين بن محمد بن القاسم (البارع) قوله: [الخفيف]

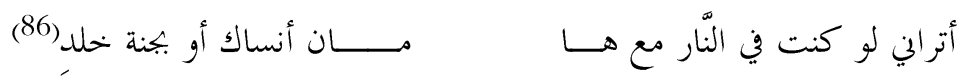

فالشاعر هنا أتى بالاستفهام لينكر ما قد حصل منه؛ ذلك لأنَّ هزة الاستفهام قد دخلت على الفعل المضارع، والشاعر هنا نراه يقدم انكاره مع الدليل، فعمد الشاعر لمثل هذا الأسلوب لبيان مكانة صديقه، أي إنه عدم نسيانه وتمسك الثاعر به أقوى من كلّ الظروف، وقد بالغ الشاعر بهذه الصداقة لأجل الصداقة من جهة، و اثبات صدقه أمام من يقصد من جهة أخرى. وقال القاسم بن عبيد الله وقد شخَّص لنا مدى حزنه وتقطع أوصاله: [الطويل]

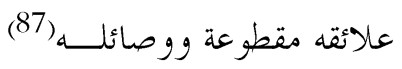

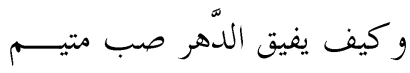

افصح الشاعر هنا عن حالته النفسية، وما كان يعانيه من ألم شديد، فخرج الاستفهام إلى معيى النفي، فلم يكن .كقدوره التغيير لشدة ضعفه وأساه، والأداة هنا زادت من ترابط تراكيب الجملة بكيث امتلَّ تأثيرها على الكلمات كلها.

$$
\text { و منه قول الحسين بن محمد القاسم (البارع): [المديد] }
$$

$$
\text { أين قلبي ما صنعت به به ت }
$$

لم يتساءل الشاعر هنا عن مكان القلب، فمكانه معروف في صدر الإنسان، وإنما أراد اظهار تحسره ولوعته واثبات حقيقة الألم نتيجة هذا الحبب، وقل اضاف الشاعر هنا دلالات معنوية أعطت التجربة الشعورية حيوية" وانفعالًا، و نلحظ في البيت اثبات الحقيقة وصدق تحسر الشاعر عن طريق نفيه بأسلوب 
كرَّ الاثارة والوله، و كان هذا الاسلوب في رسم صورة التحسر أدعى للجمال و التأثير من قوله المباشر و التصريح بحبها. وهنا نقول أنَّ الاستفهام كان في شعرهم دليلّ على تنوع الأساليب ودقة التعبير (89.

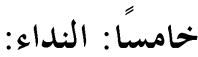
هو من الأساليب التي يستعملها الشعراء في التعبير عن ذاتهم، فضلًا عن كونه وسيلة من وسائل الانتباه،

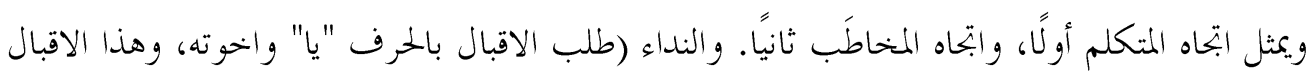

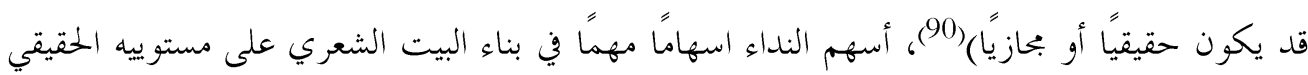

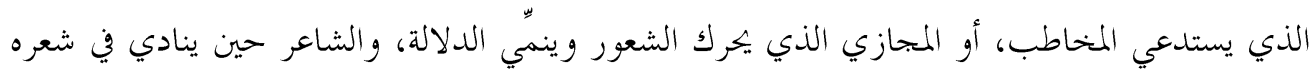

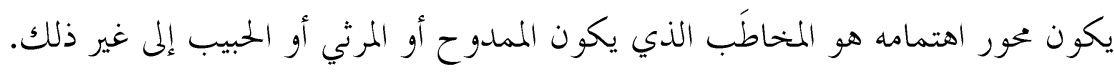

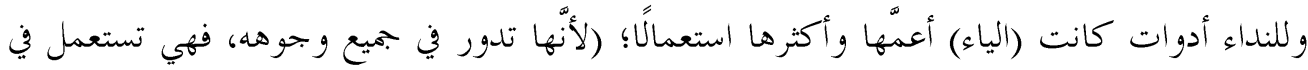

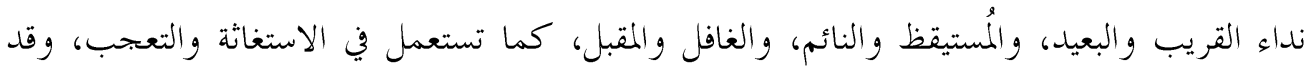

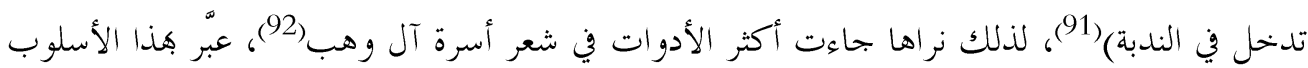

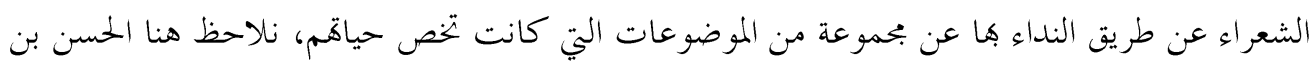

$$
\begin{aligned}
& \text { وهب يبدي تودده ويُظهر حبه لمَن كان يقصده فيقول: [بخزوء الرمل] }
\end{aligned}
$$

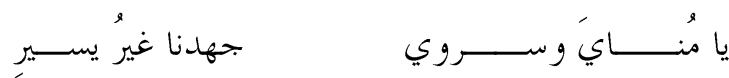

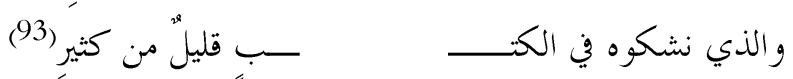

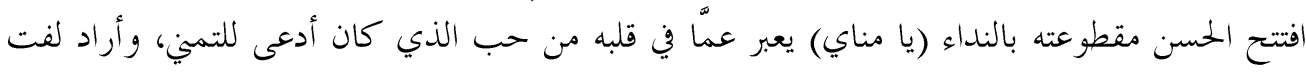

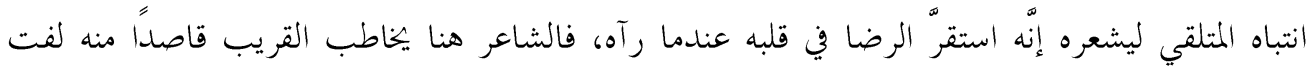

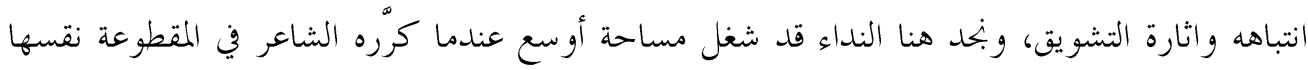
بقصد شدةّة الانتباه فيقول:

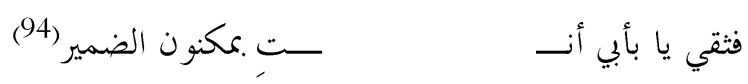

وكأنَّ الشاعر أراد تأكيد حبه فأكثر من ترديده، ويثبت صدقه لها فاكسب النداء هنا شعره معاني الني تعددت وتنوعت هي الأخرى. وقد عبّر الحسن بن وهب عن وتن أساه وحزنه على فقدان أبي تمام، فنلاحظه يناديه، وقد استقرّ حبه في قلبه، يقول: [الوافر]

$$
\text { لقينا بعدك العجب العجيبا(95) }
$$$$
\text { أبا تمام الطَّائي، إنَّا }
$$ 
فالشاعر هنا حذف أداة النداء مُختصرً" كلامه، وهذا من شأنه يعمق دلالة معاني الرثاء الذي كان يعبرِ

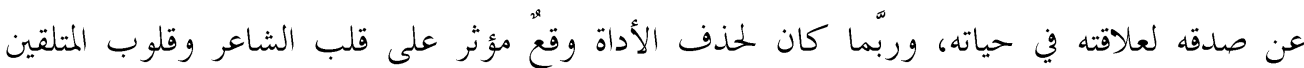

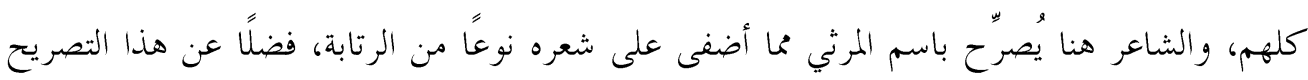
يبين مكانة المرثي.

$$
\text { وقول القاسم بن عبيد الله: [الطويل] }
$$

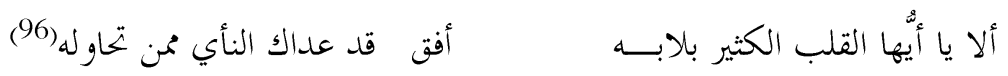

فالشاعر هنا يخاطب القلب طالبًا منه أن يفيق، فالنداء هنا يممل دلالة استنهاض الهمم واسترجاع الحال، فالشاعر هنا ابتدأ بيته بأداة الاستفتاح و التنبيه (ألا) و كأنه يتكلم هنا عن شيء حقيقي يعمق عنصر

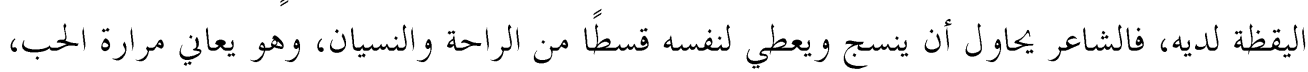

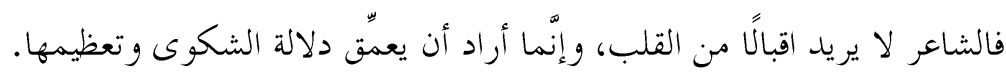

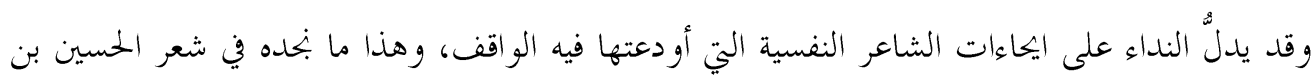
محمد (البارع) إذ يقول: [السريع]

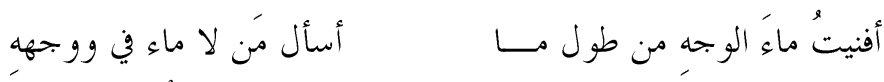

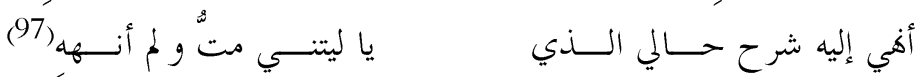

تبدو صفة التحسر والمالامة في شعره الذي يبدأ الشاعر بكوار يسرد فيه واقعه المرير، فالشاعر هنا يخاطب نفسه مستعجلًا في الحكىم عليها؛ لأنّه يراها سبب خطعأه، فالشاعر هنا يتمنى الموت تماشياً مع قوة الحلدث فيه نوع من الملالمة.

الخاتمة:

و في ختام بحثنا يمكن إجمال أهم الأمور التي نحسبها على جانب من الأهمية توصلنا ها في بكثنا هذا وهي: 1- جمع شعراء الأسرة بين فيّ القول (الشعر و النث)، و كانت هذه الصفة حسنة تُضاف إلى نتاجهم الأدبي إذ إنَّ هذه القضية لا بتحتمع إلا للقليل. 2- لغة شعرهم ونثرهم تمتاز بالمتانة وعدم استعمال الفاظ لا تنتمي للغة الفصحى، فجمعت بين الرقة والجز الة والسهولة و الصعوبة. 3- عمل شعراء أسرة آل وهب على توظيف الصيغ الخبرية والإنشائية جماليًا في أدهم، فهي و سائلهم للوصول إلى الغاية الجمالية لإثارة المتلقي. 
4- لقد انتقى أدباء أسرة آل وهب من الألفاظ والتراكيب ما يخدم عملهم الفين فاستوى شعرهم مادة مهمة يفصح عن إبداعهم في النظم. 5- يعد التقديم و التأخير من الأبواب المهمة في شعر آل وهب، إذ إنه من خصائص اللغة العربية؛ لذلك نرى هذا الأسلوب في شعرهم له شو اهد كثيرة.

6- حقق أسلوب الحذف حضورًا في شعر آل وهب وجاء في أغراض شعرهم لغاية معنوية أكسبت شعرهم نوعًا من التميزّ

7 - الاستفهام في شعر آل وهب جاء دليلًا على تنوع الأساليب، ودقة التعبير. 8- عبر شعراء الأسرة عن طريق النداء عن بحموعة من الموضوعات التي كانت تخص حياتهم.

\section{المصادر}

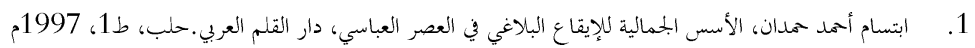

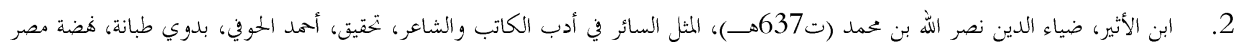

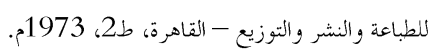

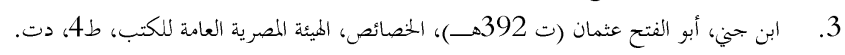
4.

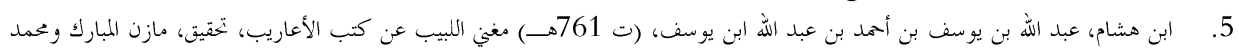

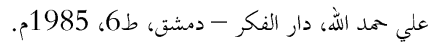

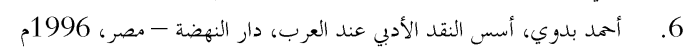

7.

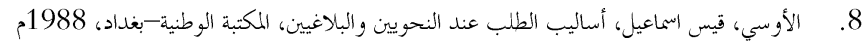

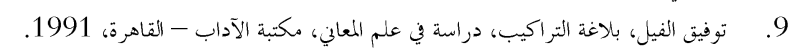

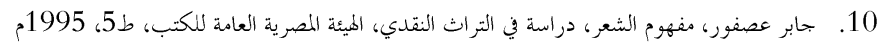

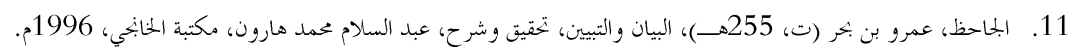

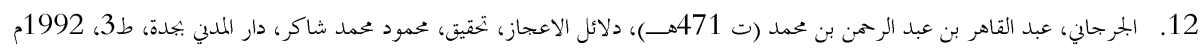

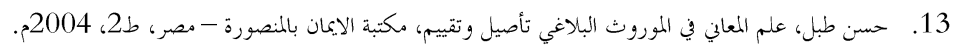

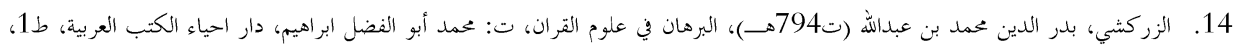

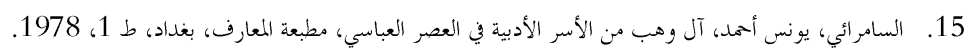

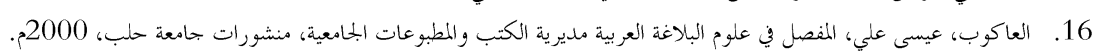

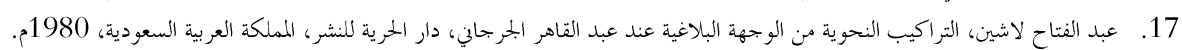

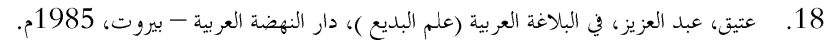

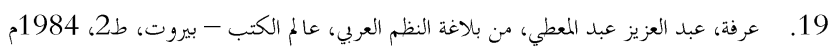

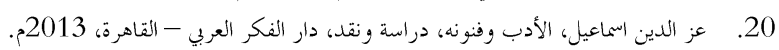

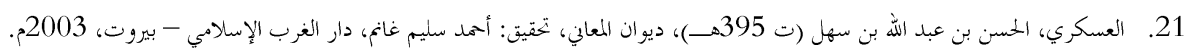

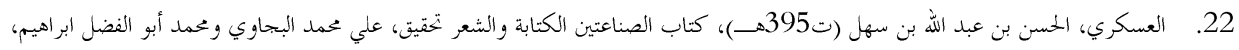

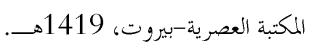




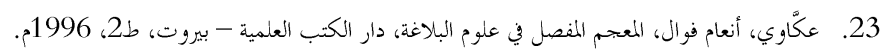

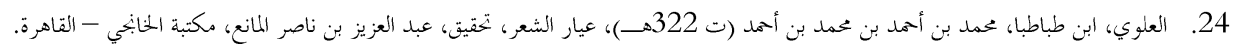

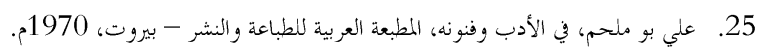

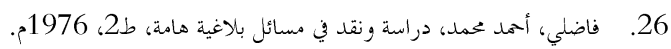

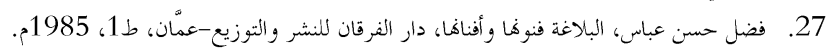

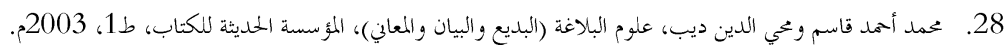

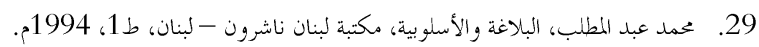

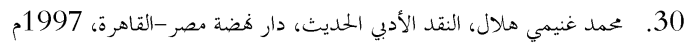

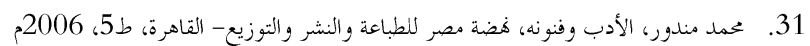

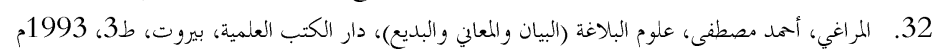

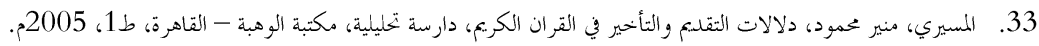

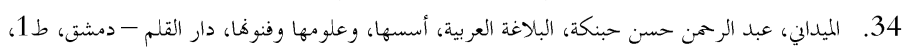

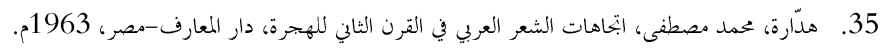

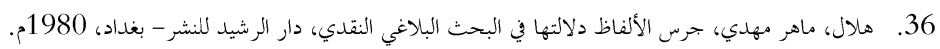

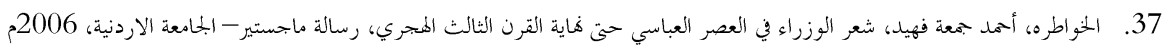

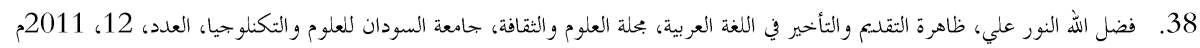

(1) جرس الألفاظ ودلالتها في البحث البلاغي والنقدي عند العرب: ماهر محمد هلال: 20.

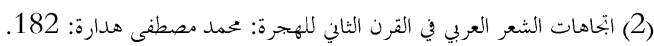

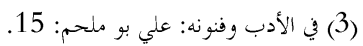

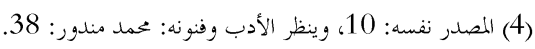

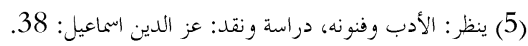

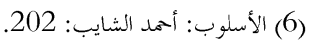

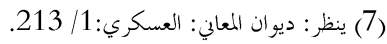
(8)

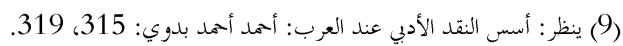

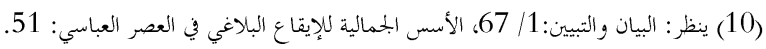

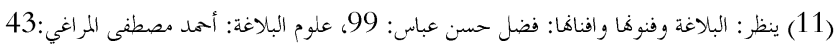

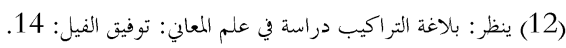

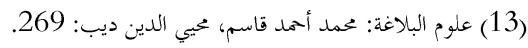
(14) آل وهب: 127 (15 اليلاغ: (15) المصدر نفسه: 281.

(16) آل وهب: 335 (16) (17) المصدر نفسه: 373. (18) المصدر نفسه: 373.

(19) آل وهب: 132 (لمطر نفسة (20) ينظر: البلاغة فنوها وأفنافا: فضل حسن: 114، بلاغة إنة التركيب، دراسة في علم المعاني: توفيق: 19- 20، دراسة ونقد في مسائل بلاغية هامة: محمد فاضلي: 68 - 69. 


$$
\begin{aligned}
& \text { (21) المفصل في علوم البلاغة العربية: } 80 . \\
& \text { (22) آل وهب: } 135 . \\
& \text { (23) آل وهب: } 137 \text { آل وهب: } 137 \\
& \text { (24) المصدر نفسه: } 281 . \\
& \text { (25) المصدر نفسه: } 128 . \\
& \text { (26) آل وهب: } 278 . \\
& \text { (27) المفصل في علوم البلاغة: } 83 .
\end{aligned}
$$

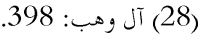

(29) في البلاغة العربية، علم المعاني: د عبد العزيز عتيق:54 البر، البلاغة العربية اسسها وعلومها وفنوفا: عبد الرهمن حسن حبنكة: 179.

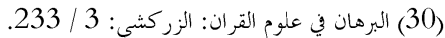

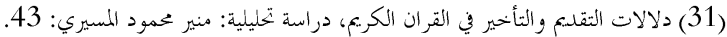

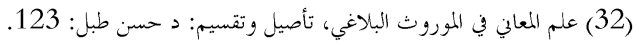

$$
\text { (33) دلائل الاعجاز: } 106 .
$$

(34) ظاهرة التقديع والتأخير في اللغة العربية: فضل اللّ النور علي: 186.

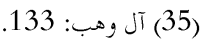

$$
\text { (36) (36) المصدر نفسه: } 134 .
$$

(37) ينظر: مغني اللبيب عن كتب الأعاريب: ابن هشام: 608 وما بعدها.

(38)

$$
\text { (39) (39) المصدر نفسه: } 277 .
$$

(40) مفهوم الشعر: جابر عصفور: 371.

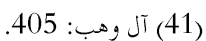

(42) البالاغة والاسلو بية: محمد عبد المطلب: 331.

(43) آل وهب: 131، شعر الحسن في الصفحات: 133، 139، 131، 151، 155. (44) المصدر نفسه : 280، وينظر : المصدر نفسه: 282.

(45) المصدر نفسه: 126.

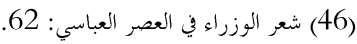

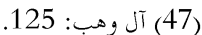

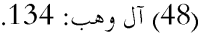

(49) المصدر نفسه: 283.

(50) (50) (50در نفسه: 402.

(51) (51) دلائل الاعجاز: 146.

(52) علوم البلاغة العر بية: المراغي: 89.

(53) ينظر: التراكيب النحوية من الوجهة البلاغية: عبد الفتاح لاشين: 164.

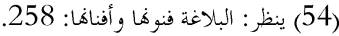

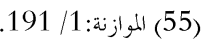

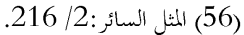

(57) ينظر: كتاب الصناعتين: 32، وينظر: : المثل السائر: 220/ 220.

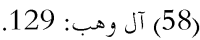

(59) ينظر: بالاغة التركيب، دراسة في علم المعاني: توفيق الفيل: 61. 


$$
\begin{aligned}
& \text { (60) (60) آل وهب: } \\
& \text { (61) النقد الأدبي الحديث: محمد غنيمي هلال: } 429 . \\
& \text { (62) آل وهب: } 124 \text { النق الأب } 124 . \\
& \text { (63) ينظر: المصدر نفسه: 125، 131 132، 133، 141، } 146 .
\end{aligned}
$$

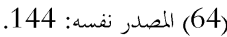

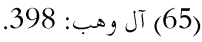

(66) ينظر: المثل السائر : 1 / 218، 220.

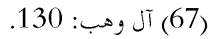

(68) - (68) المصدر نفسه: 139.

(69) دلائل الاعجاز: 153.

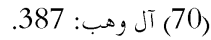

(71) (71) آل وهب: 403 ودب:

(72) (72) المصدر نفسه: 127.

(73) المصدر نفسه: 130، 139 139، 144، 147، 162، 164، 169، 169، 180.

(74) المصدر نفسه: 132.

(75) (75) المصدر نفسه: 132.

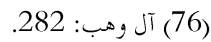

(77) المصدر نفسه: 402.

(78)

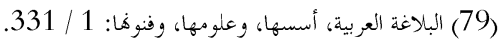

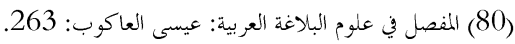

282.

(82) المصدر نفسه: 161 آل وهب: 161 (83)

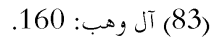

(85) ينظر : من باغة النظم العربي: عبد العزيز عبد المعطي:278/ 103.

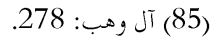

(86) المصدر نفسه: 399.

(87) (88) المصدر نفسه: 373.

(88) (88) آل وهب:

(89) ينظر: المصدر نفسه: 126، 132، 139، 153، 154، 282، 334، 333، 373، 387، 398.

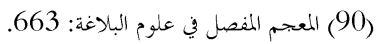

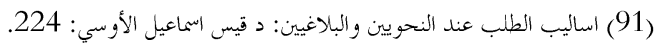

(92) ينظر: آل وهب: 132، 134، 136، 138، 141، 143، 148، 152، 154، 156، 161، 168، 173، 281، 282، 282، 334، 335،

.409، 373، 403، 405، 405

(93) المصدر نفسه: 147 (9)

(94) (95) المصدر نفسه: 147.

(95)

(96) المصدر نفسه: 373 آل وهب:

(97) المصدر نفسه: 407 (لمصدر نفه: 